\title{
Determination of density and excess molar volume of dimethyl sulfoxide + 1-allyl-3- methylimidazolium chloride mixtures at high pressure
}

\author{
Laura de Pablo Nisa ${ }^{1,2}$, José J. Segovia ${ }^{2}$, Ángel Martín, M. \\ Carmen Martín ${ }^{2}$, M. Dolores Bermejo ${ }^{{ }^{*}}$
}

${ }^{1}$ High Pressure Process Group, Department of Chemical Engineering and Environmental Technology, University of Valladolid, Spain

${ }^{2}$ TERMOCAL Research Group, Thermodynamics and Calibration, University of Valladolid, Escuela de Ingenierías Industriales, Paseo del Cauce 59, E-47011 Valladolid, Spain

*Corresponding author. Email: mdbermejo@iq.uva.es

Tel.: +34983184077

Fax: + 34983184865

\begin{abstract}
In this work, densities of dimethyl sulfoxide + 1-allyl-3-methylimidazolium chloride mixtures have been experimentally determined with a vibrating tube densimeter. Densities were measured at temperatures between 293.15 and $373.15 \mathrm{~K}$ and molar fractions of dimethyl sulfoxide $\mathrm{x}_{\mathrm{DMSO}}=$ $0,0.050 .1,0.15,0.25,0.5,0.75,0.9$ and 1 at pressures in the range $\mathrm{P}=[0.1,35] \mathrm{MPa}$. It was found that density increases with ionic liquid concentration and with pressure and decrease with temperature. Excess molar volumes were calculated resulting in negative values with a maximum of non-ideality at DMSO concentration of $\mathrm{x}_{\mathrm{DMSO}}=0.5$. The excess molar values were less negative at high pressures. At $\mathrm{T}=330 \mathrm{~K}$ a maximum in the excess molar values was observed at several concentrations. Density was correlated as a function of temperature, pressure and concentration with an average relative deviation of $0.12 \%$.
\end{abstract}


Keywords: ionic liquid, 1-ally-3-methylimidazolium Chloride, dimethyl sulfoxide, density, excess molar volume, correlation.

\section{Graphical Abstract}

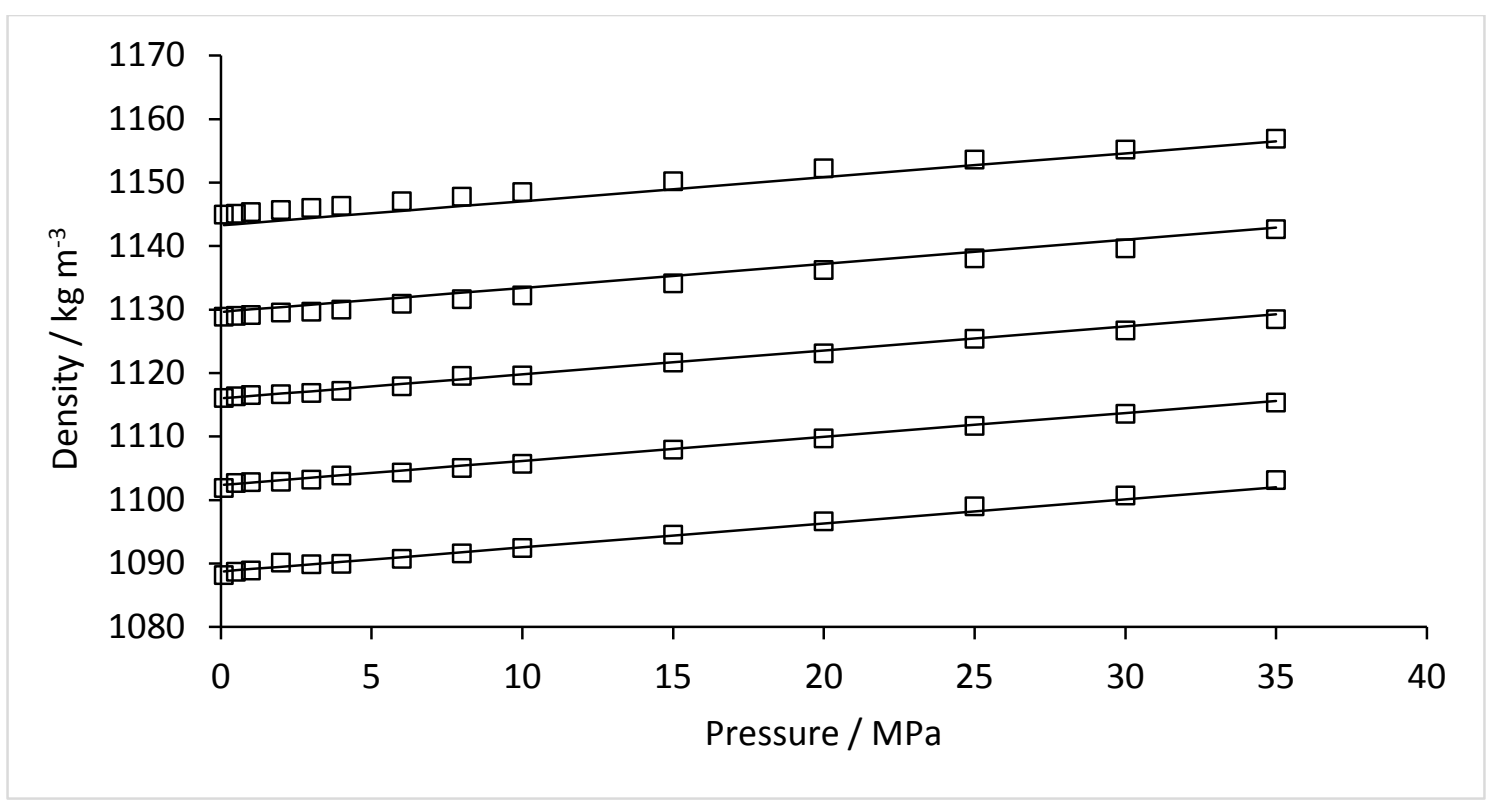

\section{Symbols}

ARD \% Average relative deviation

DMSO Dimethyl sulfoxide

IL Ionic liquid

$\mathrm{M}_{\mathrm{i}} \quad$ Molecular weight of the substance i in $\mathrm{g} \mathrm{cm}^{-3}$

$\mathrm{V}^{\mathrm{E}} \quad$ Molar excess volume in $\mathrm{cm}^{3} \mathrm{~mol}^{-1}$

VTD Vibrating Tube Densimeter

$\mathrm{X}_{\mathrm{i}}$

Molar concentration of the substance i 


\section{Introduction:}

Currently, and due to the strong need of environmentally benign technologies, the possibilities of using so-called ionic liquids (ILs) are being explored. These substances are characterized by being composed only by ions whose size are irregular and large enough to prevent the formation of a solid net. Thus, they are liquid at room temperatures. Therefore, ILs can be defined as salts in liquid phase [1]. Their most notable property is its negligible vapor pressure and high solvation power for multitude of components, both organic and inorganic. These properties make them attractive for their use as an alternative to traditional and highly volatile organic solvents. By combining different anions and cations, millions of ionic liquids can be synthetized and their properties can be tuned by simply changing, cations, anions or the length of the alkyl chain substituents [2]. Among them, imidazolium based ionic liquids with acetate, chloride or alkylphosphate anions stand out for their capacity of dissolving cellulose and other natural polymers.

Cellulose is the most abundant organic substance on earth and its processing can lead to obtain high added-value substances [3]. Most conventional processes for cellulose transformation are based on the use of highly pollutant solvents or extreme operational conditions. Thus, the development of process for cellulose transformation using ionic liquids has attracted a lot of attention in the last years [4-7]. One of the main inconvenients for the development of cellulose processing in ionic liquid is the high viscosity of ILs [8], especially in the case of those with chloride anion. In addition, the dissolution of cellulose in ILs causes the viscosity of the mixture to increase significantly. As a consequence, ionic liquids are often used in combination with co- 
solvents in order to reduce the viscosity, or enhance the transport properties [9], because it is well known that molecular solvents decrease the viscosity of alkyl-imidazolium ionic liquids while other impurities as chloride increase it [10,11].In the case of cellulose processing it is important that the co-solvent chosen do not cause the precipitation of cellulose thus, dimethyl formamide or most frequently dimethyl sulfoxide (DMSO) are used [12-14]. Thus, it is important to know the physical properties of these mixtures at different operational conditions

In literature, it is possible to find several published works where the density and viscosity of several imidazolium chloride based ionic liquids are determined along with co-solvents or impurities. For example, Lv and coworkers [15], measured the effect of the DMSO in the viscosity of the ionic liquid + cellulose mixtures and concluded that the addition of DMSO in cellulose/AmimCl or cellulose/BmimCl decreases dramatically the viscosity of them. Densities, excess volume, viscosities and other thermodynamics properties of aqueous mixtures of alkylimidazolium chloride based IL’s has also been studied among others by Sastry et al. [16], Tariq et al. [17], Liu et al. [18], Sing \& Kumar [19] and Gomez et al. [20]. Properties of aqueous mixtures of AmimCl by Xu et al. [21], Wu et al. [22], and Jimenez and co-workers [23]. Kumar et al. [24], proceed to measure the density of mixtures ethylene glycol + alkyl-imidazolium chloride ionic liquids at atmospheric pressure. Lopes et al. [25] measured the density and viscosity of mixtures $\mathrm{CO}_{2} / \mathrm{AmimCl}$ and correlate the viscosity with a modified equation from Seddon et al. [10]. In general, it is observed that density decreases with temperature and with co-solvent concentration.

Some other authors have studied the influence of the pressure in the density. For example, Tomé et al. have studied the change of the density of pure imidazolium based Ionic Liquids with the pressure, and correlated this data with the Tait equation [26], Machida et al. also measured the density of L-Lactate-containing Ionic Liquids up to $200 \mathrm{MPa}$ [27], and Safarov et al. determined the density and viscosity of pure 1-butyl-3-methylimidazolium acetate [Bmim][Ac] up to 140 MPa [28]. Gardas et al. [29] measured the density of imidazolium-based Ionic Liquids and then 
correlated it with the Tait equation. All of them found that the density of ionic liquids increased with pressure. There is also a number of works presenting densities of different organic liquids + different organic solvents under pressure [30-33], observing also that the density of the mixture increases with pressure.

In the literature, examples of both positive and negative excess molar volumes in co-solvent + ionic liquid mixtures can be found. In [34] Bahadur et al. studied the excess molar volume in mixtures of ionic liquid and water, and they concluded that excess molar volumes are the result of two competitive effects, a positive effect caused bythe reduction of self-association between molecules due to the influence of the hydrogen bonds or Van der Waals interactions, and a negative effect that could be a result of a better packing caused of polar interactions between molecules. In mixtures of co-solvents with imidazolium chloride or acetate ionic liquids it is reported that excess molar volume is decreasing with increasing cosolvent concentration until reaching a minimum for molar fractions of around 0.6-0.7 [20,23]. Sandhya et al. studied the influence of the temperature and alcohol's length in the excess volume, and they found that when the temperature and the alcohol chain length increases, the mixture becomes less ideal, and the point where the excess molar volume is maximum moves to higher compositions [35]. On the other hand, Makhtarani et al. measured the behavior of binary mixtures of pyridinium based ionic liquid plus water, and they found that the mixtures have positive excess molar volume, and it is less ideal when the temperature increases [36].To the best of our knowledge, there are no experimental data of densities and excess molar volume of mixtures DMSO + AmimCl.

In this work the density of mixtures of DMSO + AmimCl at various conditions of temperature, pressure and concentration are presented. Excess molar volumes were calculated using the experimental density data. Density was correlated as a function of temperature, pressure and composition. 


\section{Experimental:}

\subsection{Materials.}

For the calibration, pure water and vacuum were used. Density of toluene was measured in order to check the calibration. Both compounds, water and toluene were supplied by Sigma Aldrich with purities of $100 \%$ and $99.8 \%$ respectively. The DMSO has a purity of $98 \%$ and was supplied by Sigma - Aldrich with a humidity of $\approx 200 \mathrm{ppm}$. The 1-allyl-3-methylimidazolium chloride supplied by Iolitec (assay $(\mathrm{NMR})=98 \%$; 1-Allyl-3-methylimidazolium (IC)= 99.9\%; Chloride $(\mathrm{IC})=99.9 \%$; 1 -Methylimidazole $(\mathrm{IC})<1 \%$ and Water $(\mathrm{KF})=0.2467 \%)$. The ionic liquid was further dried by applying a level of vacuum of $10^{-2}$ mbar while stirred at temperature of $86^{\circ} \mathrm{C}$. Good results of humidity were obtained after this procedure as it is shown in Table 1 . In addition, the ionic liquid was carefully handled in order to avoid absorption of water from the air, as it is explained below.

Table 1: Water content in mixtures DMSO + AmimCl

\begin{tabular}{cc} 
XDMSo / mol $/ \mathrm{mol}$ & Xwater $/ \mathrm{mol} / \mathrm{mol}$ \\
\hline 0.000 & 0.013 \\
0.048 & 0.015 \\
0.098 & 0.016 \\
0.147 & 0.014 \\
0.248 & 0.006 \\
0.495 & 0.011 \\
0.729 & 0.021 \\
0.893 & 0.008 \\
0.999 & 0.001 \\
Uncertainty of the molar fraction is $0.001 \mathrm{~mol} / \mathrm{mol}$
\end{tabular}

2.2 Description of the equipment 
The mixtures were prepared gravimetrically by using a high precision balance (Sartorius Basic BA 310P, precision $=0.001 \mathrm{~g}$ ) under nitrogen atmosphere, in which the humidity is kept below 30\%. The water content of IL, DMSO and of their mixtures was measured with Karl - Fischer Coulometric titration using Mettler Toledo C20 KF, taking at least three measurements per sample.

Densities of these mixtures at various temperatures and pressures, from atmospheric pressure to $35 \mathrm{MPa}$, were performed in a vibrating tube densimeter (VTD) model Anton Paar DMA 514, connected to a frequency meter Anton Paar DMA 60. A schematic diagram of the equipment is shown in Figure 1. The basis of a vibrating tube densimeter is that the resonance frequency of a body immersed in a fluid depends on the density. The vibrating tube viscometer is a simple device consisting mainly of a thin " $U$ " tube filled with the liquid which density we want to determine. The tube is surrounded by mineral oil bath, Julabo $\mathrm{F} 25$, whose purpose is merely to keep constant its temperature. A Pt100 thermometer is placed in the curved part of the " $\mathrm{U}$ " (where the resonance frequency is precisely measured) and a temperature controller, Julabo HE, integrated in the above mentioned thermal bath keeps the temperature constant. The Pt100 thermometer has an uncertainty of $\pm 0.05 \mathrm{~K}$ and the frequency meter has an uncertainty of $\pm 7.510^{-3} \mu \mathrm{s}$. The pressure is measured with a digital manometer GE Drunk DPI 104 and controlled by a manually operated piston. The manometer has an uncertainty of \pm 0.02 bar. To calibrate is necessary to measure the response of the equipment in two different conditions, firstly with the tube under vacuum and secondly with a fluid of known density, which in this case, high purity distilled water was chosen. It is important that the conditions of pressure and temperature of these calibrations are the same that the final intended measuring conditions. Previous to the measurement of the mixtures DMSO + AmimCl, toluene density was measured in order to compare with the available data on Refprop [37]. The equipment was previously described in [38,39]. 


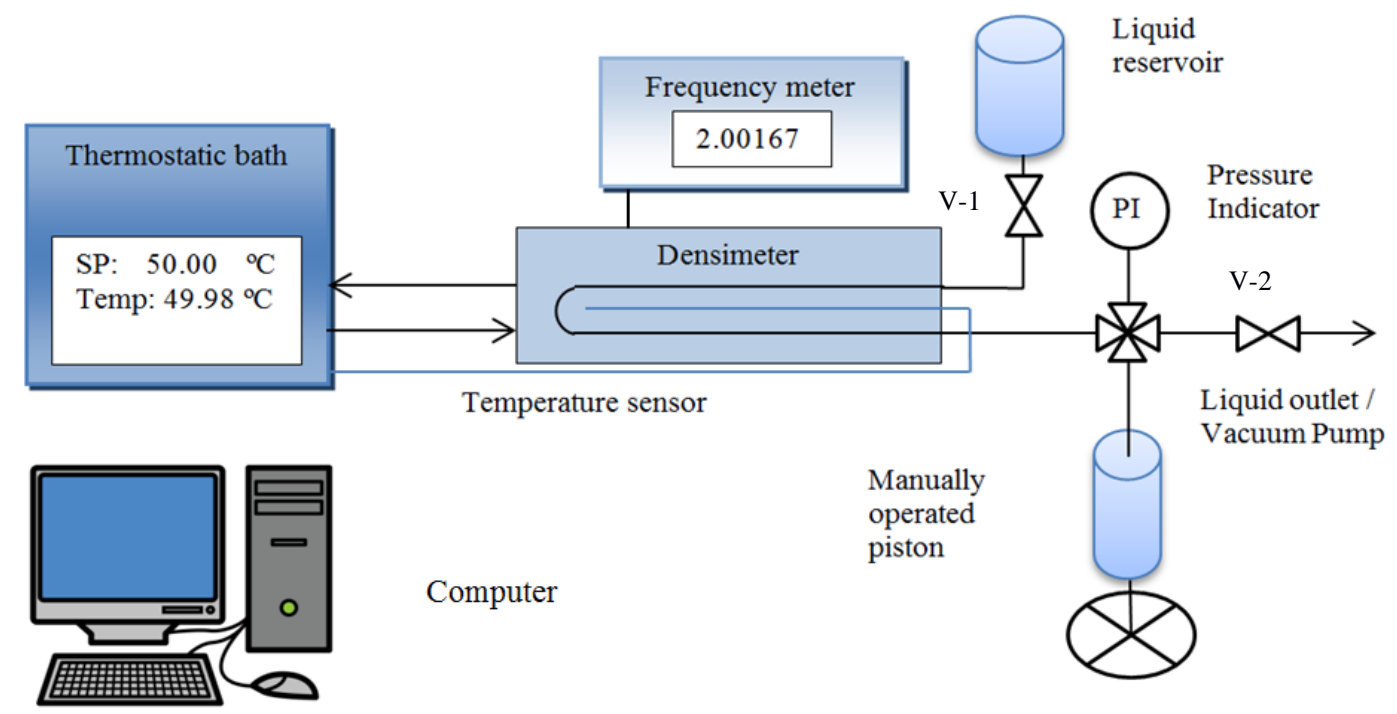

Figure 1: Installation scheme.

\subsection{Densimeter loading and measuring procedures}

Ionic liquids are in general very hygroscopic, so they must be handled with extreme care in order to avoid their humidification. Thus to charge the mixture in the densimeter the following procedure was used: first of all, a vacuum pump is connected to the pipe, and then, when the pressure inside is lower than $10^{-2} \mathrm{mPa}$ the pump is stopped and the valve V-2 is closed. Secondly, a funnel filled with the mixture is connected to the pipe. In the next step, the valve V-1 is opened and the mixture enters and fills the equipment. It is important to avoid that air bubbles enter in the pipe because they can modify the density measurements.

While working with the highly viscous mixture, during the filling step, the bath temperature is set to $80^{\circ} \mathrm{C}$ so the mixture can flow easily through the pipe. Finally, all valves are closed, so the mixture keeps insulated from water.

After the mixture is introduced inside the equipment, the bath temperature is set to the first temperature, and then the densities of the mixture at the specified temperature in all range of 
pressures are measured. Finally, the next temperature is set up in the bath and the process is repeated.

\section{Evaluation of the uncertainty}

In this work the calibration method for the vibrating tube densimeter developed Lagourette et al. [40] and modified by Comuñas et al. [39] was used. In this method, the density of one fluid depends on the oscillation period as is described in the equation ( 1 ):

$$
\rho(T, P)=A(T) \tau^{2}(T, P)-B(T, P)
$$

With two sets of data, for (vacuum and high purity water) it is possible to determine the calibration constants "A" and "B" that are the characteristic parameters of the apparatus, for every operational condition. In this work, vacuum and high purity water were used as reference fluids.

Equations of uncertainty of the vibrating tube densimeter can be calculated from [38] following the law of propagation of uncertainty described in JCGM 100: 2008 [41].

Table 2: Uncertainty budget for the vibrating tube densimeter. Values calculated for density of $x_{D M S O}=0.247, P=1$

MPa and $T=333.15 \mathrm{~K}$.

\begin{tabular}{cccccc}
\hline \multirow{2}{*}{ Uncertainty } & & Units & Estimate & Divisor & $\mathrm{u}(\mathrm{x}) / \mathrm{kg} / \mathrm{m} 3$ \\
\hline $\mathrm{u}(\rho$ ref $)$ & Reference Material & $\mathrm{kg} / \mathrm{m}^{3}$ & 0.1 & 2 & 0.058 \\
\hline \multirow{2}{*}{$\mathrm{u}(\mathrm{T})$} & Calibration & & 0.050 & 2 & \\
& Resolution & $\mathrm{K}$ & 0.010 & $2 \sqrt{3}$ & 0.0257 \\
& Repeatability & & 0.005 & 1 & \\
$\mathrm{u}(\mathrm{P})$ & Calibration & & 0.02 & 2 & 0.014 \\
& Resolution & $\mathrm{MPa}$ & 0.01 & $2 \sqrt{3}$ & \\
\hline $\mathrm{u}(\tau$ water $)$ & Repeatability & & 0.01 & 1 & $2.34 \mathrm{E}-06$ \\
& Repeatability & & $2.32 \mathrm{E}-06$ & 1 & $2 \sqrt{3}$ \\
\hline
\end{tabular}




\begin{tabular}{ccccc}
\hline $\mathrm{u}(\tau$ void $)$ & $\begin{array}{c}\text { Repeatability } \\
\text { Resolution }\end{array}$ & $\mu \mathrm{s}$ & $\begin{array}{c}1.77 \mathrm{E}-06 \\
1.00 \mathrm{E}-06\end{array}$ & $\begin{array}{c}1 \\
2 \sqrt{3}\end{array}$ \\
\hline $\mathrm{u}(\mathrm{A}(\mathrm{T}))$ & $\mathrm{kg} \mathrm{m}^{-3} \mu \mathrm{s}^{2}$ & & 0.1 \\
\hline $\mathrm{u}(\mathrm{B}(\mathrm{T}, \mathrm{P}))$ & $\mathrm{kg} \mathrm{m}^{-3}$ & & 0.5 \\
\hline $\mathrm{U}(\mathrm{A}(\mathrm{T}))$ & $\mathrm{kg} \mathrm{m}^{-3} \mu \mathrm{s}^{2}$ & $\mathrm{k}=2$ & 0.3 \\
\hline $\mathrm{U}(\mathrm{B}(\mathrm{T}, \mathrm{P}))$ & $\mathrm{kg} \mathrm{m}^{-3}$ & $\mathrm{k}=2$ & 1.0 \\
\hline $\mathrm{u}(\rho)$ & $\mathrm{kg} \mathrm{m}^{-3}$ & & 0.7 \\
\hline $\mathrm{U}(\rho)$ & $\mathrm{kg} \mathrm{m}^{-3}$ & $\mathrm{k}=2$ & 1.5 \\
\hline $\mathrm{U}(\rho)$ & $\mathrm{kg} \mathrm{m}^{-3} / \mathrm{kg} \mathrm{m}^{-3}$ & $\mathrm{k}=2$ & $1.3 \mathrm{E}-03$ \\
\hline
\end{tabular}

The uncertainty achieved has the same order of magnitude as that obtained by others authors using the same or similar equipment. [38]

Finally, the density of toluene measured with the densimeter is compared to data from Refprop [37] resulting in a proper fit with the experimental data.

\section{Experimental results}

\subsection{Densities of DMSO + AmimCl.}

Densities at different DMSO molar fractions as a function of pressure and temperature are presented in tables from Table 2 to Table 11. Density of a mixture of $\mathrm{x}_{\mathrm{DMSO}}=0.729$ at various temperatures is plotted versus pressures in Figure 2. It is observed that density increases linearly with pressure and decrease with temperature. The same behavior is observed for all the concentrations studied.

Table 3: Densities of pure DMSO, $\chi_{\mathrm{H} 2 \mathrm{O}}=0.001$.

Density / $\mathrm{kg} \mathrm{m}^{-3}$

Pressure / bar Temperature / K




\begin{tabular}{l|lllll}
\hline \multicolumn{1}{l}{} & 293.15 & 313.15 & 333.15 & 353.15 & 373.15 \\
\hline 1.00 & 1098.5 & 1078.9 & 1061.0 & 1040.6 & 1019.9 \\
5.00 & 1099.8 & 1079.2 & 1061.2 & 1041.1 & 1020.4 \\
10.00 & 1100.1 & 1079.6 & 1061.6 & 1041.1 & 1020.7 \\
20.00 & 1100.7 & 1080.1 & 1061.9 & 1041.9 & 1021.5 \\
30.00 & 1101.3 & 1080.7 & 1062.5 & 1042.6 & 1022.5 \\
40.00 & 1101.8 & 1081.1 & 1063.1 & 1043.2 & 1023.2 \\
60.00 & 1102.8 & 1082.9 & 1064.3 & 1044.7 & 1024.5 \\
80.00 & 1103.9 & 1083.5 & 1065.5 & 1046.1 & 1026.0 \\
100.00 & 1105.0 & 1084.7 & 1066.8 & 1047.5 & 1027.6 \\
150.00 & 1106.1 & 1087.6 & 1069.9 & 1051.0 & 1031.4 \\
200.00 & 1109.0 & 1090.7 & 1073.0 & 1054.4 & 1035.0 \\
250.00 & 1111.1 & 1093.2 & 1076.0 & 1057.3 & 1038.6 \\
300.00 & 1113.6 & 1095.8 & 1078.9 & 1060.5 & 1042.2 \\
350.00 & 1116.1 & 1098.5 & 1081.7 & 1063.6 & 1045.6 \\
\hline
\end{tabular}

Expanded uncertainty of the density $U(\rho)=1.5 \mathrm{~kg} \mathrm{~m}^{-3}$, expanded uncertainty of the temperature $U(T)=0.05 \mathrm{~K}$, expanded uncertainty of the pressure $U(P)=0.03$ bar, expanded uncertainty of the composition $U(x)=0.001$ with $k=2$.

Table 4: Densities of mixture DMSO + AmimCl, $x_{\text {DMSO }}=0.893, \chi_{\text {H2O }}=0.008$.

Density / $\mathrm{kg} \mathrm{m}^{-3}$

\begin{tabular}{c|ccccc}
\hline \multirow{2}{*}{ Pressure / bar } & \multicolumn{5}{c}{ Temperature / K } \\
\hline 1.00 & 293.15 & 313.15 & 333.15 & 353.15 & 373.15 \\
\hline 5.00 & 1115.3 & 1097.1 & 1081.0 & 1062.6 & 1044.5 \\
10.00 & 1115.4 & 1097.3 & 1081.2 & 1063.1 & 1045.0 \\
20.00 & 1115.8 & 1097.6 & 1081.4 & 1063.2 & 1046.0 \\
30.00 & 1116.2 & 1098.2 & 1082.0 & 1063.7 & 1045.7 \\
40.00 & 1117.1 & 1098.6 & 1082.5 & 1064.3 & 1046.4 \\
60.00 & 1118.30 & 1100.3 & 1084.2 & 1066.2 & 1048.3 \\
80.00 & 1119.0 & 1101.2 & 1085.2 & 1067.4 & 1049.5 \\
100.00 & 1119.9 & 1102.3 & 1086.5 & 1068.6 & 1050.8 \\
150.00 & 1122.2 & 1104.8 & 1089.1 & 1071.4 & 1054.2 \\
200.00 & 1124.8 & 1107.2 & 1091.7 & 1074.3 & 1057.2 \\
250.00 & 1126.7 & 1109.7 & 1094.3 & 1077.4 & 1060.3 \\
300.00 & 1128.7 & 1112.0 & 1096.8 & 1080.0 & 1063.2 \\
\hline
\end{tabular}




\begin{tabular}{l|rrrrr}
350.00 & 1130.9 & 1114.3 & 1099.3 & 1082.6 & 1066.3
\end{tabular}

Expanded uncertainty of the density $U(\rho)=1.5 \mathrm{~kg} \mathrm{~m}^{-3}$, expanded uncertainty of the temperature $U(T)=0.05 \mathrm{~K}$, expanded uncertainty of the pressure $U(P)=0.03$ bar, expanded uncertainty of the composition $U(x)=0.001$ with $k=2$.

Table 5: Densities of mixture DMSO + AmimCl, $x_{\mathrm{DMSO}}=0.729, x_{\mathrm{H} 2 \mathrm{O}}=0.021$.

\begin{tabular}{c|llccc}
\multicolumn{5}{c}{ Density / $\mathrm{kg} \mathrm{m}^{-3}$} \\
\hline \multirow{2}{*}{ Pressure / bar } & \multicolumn{5}{c}{ Temperature / K } \\
\hline 1.00 & 293.15 & 313.15 & 333.15 & 353.15 & 373.15 \\
\hline 5.00 & 1115.3 & 1097.1 & 1081.0 & 1062.6 & 1044.5 \\
10.00 & 1115.4 & 1097.3 & 1081.2 & 1063.1 & 1045.0 \\
20.00 & 1115.8 & 1097.6 & 1081.4 & 1063.2 & 1046.0 \\
30.00 & 1116.2 & 1098.2 & 1082.0 & 1063.7 & 1045.7 \\
40.00 & 1116.6 & 1098.6 & 1082.5 & 1064.3 & 1046.4 \\
60.00 & 1117.1 & 1099.1 & 1083.1 & 1064.9 & 1047.1 \\
80.00 & 1118.3 & 1100.3 & 1084.2 & 1066.2 & 1048.3 \\
100.00 & 1119.0 & 1101.2 & 1085.2 & 1067.4 & 1049.5 \\
150.00 & 1119.9 & 1102.3 & 1086.5 & 1068.6 & 1050.8 \\
200.00 & 1122.2 & 1104.8 & 1089.1 & 1071.4 & 1054.2 \\
250.00 & 1124.8 & 1107.2 & 1091.7 & 1074.3 & 1057.2 \\
300.00 & 1126.7 & 1109.7 & 1094.3 & 1077.4 & 1060.3 \\
350.00 & 1128.7 & 1112.0 & 1096.8 & 1080.0 & 1063.2 \\
\hline
\end{tabular}

Expanded uncertainty of the density $U(\rho)=1.5 \mathrm{~kg} \mathrm{~m}^{-3}$, expanded uncertainty of the temperature $U(T)=0.05 \mathrm{~K}$, expanded uncertainty of the pressure $U(P)=0.03$ bar, expanded uncertainty of the composition $U(x)=0.001$ with $k=2$.

Table 6: Densities of mixture DMSO + AmimCl, $x_{\text {DMSO }}=0.496, x_{H 2 O}=0.011$.

Density / $\mathrm{kg} \mathrm{m}^{-3}$

\begin{tabular}{c|ccccc}
\hline \multirow{2}{*}{ Pressure / bar } & \multicolumn{5}{c}{ Temperature / K } \\
& 293.15 & 313.15 & 333.15 & 353.15 & 373.15 \\
\hline 1.00 & 1144.9 & 1128.8 & 1116.1 & 1101.9 & 1088.2 \\
5.00 & 1145.1 & 1129.0 & 1116.3 & 1102.7 & 1088.7 \\
10.00 & 1145.3 & 1129.1 & 1116.5 & 1102.8 & 1088.9 \\
20.00 & 1145.7 & 1129.5 & 1116.7 & 1102.8 & 1090.1 \\
\hline
\end{tabular}




\begin{tabular}{l|lllll}
\hline 30.00 & 1146.0 & 1129.7 & 1116.8 & 1103.2 & 1089.9 \\
40.00 & 1146.3 & 1130.0 & 1117.2 & 1103.9 & 1090.0 \\
60.00 & 1147.1 & 1130.9 & 1117.9 & 1104.3 & 1090.8 \\
80.00 & 1147.8 & 1131.6 & 1119.5 & 1105.0 & 1091.6 \\
100.00 & 1148.5 & 1132.2 & 1119.6 & 1105.7 & 1092.5 \\
150.00 & 1150.2 & 1134.1 & 1121.6 & 1107.9 & 1094.6 \\
200.00 & 1152.3 & 1136.2 & 1123.1 & 1109.7 & 1096.6 \\
250.00 & 1153.6 & 1138.0 & 1125.4 & 1111.7 & 1099.0 \\
300.00 & 1155.2 & 1139.6 & 1126.7 & 1113.5 & 1100.7 \\
350.00 & 1156.9 & 1142.6 & 1128.4 & 1115.4 & 1103.1 \\
\hline
\end{tabular}

Expanded uncertainty of the density $U(\rho)=1.5 \mathrm{~kg} \mathrm{~m}^{-3}$, expanded uncertainty of the temperature $U(T)=0.05 \mathrm{~K}$, expanded uncertainty of the pressure $U(P)=0.03$ bar, expanded uncertainty of the composition $U(x)=0.001$ with $k=2$.

Table 7: Densities of mixture DMSO + AmimCl, $x_{\mathrm{DMSO}}=0.248, x_{\mathrm{H} 2 \mathrm{O}}=0.006$.

Density / $\mathrm{kg} \mathrm{m}^{-3}$

\begin{tabular}{c|ccccc}
\hline \multirow{2}{*}{ Pressure / bar } & \multicolumn{5}{c}{ Temperature / K } \\
\hline 1.00 & 293.15 & 313.15 & 333.15 & 353.15 & 373.15 \\
\hline 5.00 & 1150.4 & 1137.9 & 1124.4 & 1112.9 & 1100.9 \\
10.00 & 1150.5 & 1137.9 & 1124.5 & 1113.3 & 1101.3 \\
20.00 & 1150.7 & 1138.1 & 1124.5 & 1113.30 & 1101.5 \\
30.00 & 1151.2 & 1138.4 & 1124.9 & 1113.53 & 1101.7 \\
40.00 & 1151.4 & 1138.6 & 1125.2 & 1113.82 & 1102.2 \\
60.00 & 1151.7 & 1138.9 & 1125.5 & 1114.12 & 1102.5 \\
80.00 & 1152.4 & 1139.4 & 1126.0 & 1114.63 & 1103.0 \\
100.00 & 1153.0 & 1140.0 & 1126.6 & 1115.40 & 1103.6 \\
150.00 & 1153.5 & 1140.4 & 1127.5 & 1116.17 & 1104.3 \\
200.00 & 1155.1 & 1142.1 & 1129.0 & 1117.89 & 1106.0 \\
250.00 & 1157.0 & 1143.5 & 1130.6 & 1119.73 & 1108.7 \\
300.00 & 1158.1 & 1145.0 & 1132.6 & 1121.35 & 1110.0 \\
350.00 & 1159.8 & 1146.6 & 1134.1 & 1123.32 & 1111.7 \\
\hline
\end{tabular}

Expanded uncertainty of the density $U(\rho)=1.5 \mathrm{~kg} \mathrm{~m}^{-3}$, expanded uncertainty of the temperature $U(T)=0.05 \mathrm{~K}$, expanded uncertainty of the pressure $U(P)=0.03$ bar, expanded uncertainty of the composition $U(x)=0.001$ with $k=2$. 
Table 8: Densities of mixture DMSO + AmimCl, $x_{\text {DMSO }}=0.147, x_{\mathrm{H} 2 \mathrm{O}}=0.014$.

Density / $\mathrm{kg} \mathrm{m}^{-3}$

\begin{tabular}{c|ccccc}
\hline \multirow{2}{*}{ Pressure / bar } & \multicolumn{5}{c}{ Temperature / K } \\
\hline 1.00 & 293.15 & 313.15 & 333.15 & 353.15 & 373.15 \\
\hline 5.00 & 1150.1 & 1138.8 & 1125.3 & 1113.3 & 1101.7 \\
10.00 & 1150.3 & 1138.9 & 1125.4 & 1113.9 & 1102.1 \\
20.00 & 1150.8 & 1139.2 & 1125.6 & 1113.8 & 1102.3 \\
30.00 & 1151.0 & 1139.7 & 1126.4 & 1114.3 & 1103.1 \\
40.00 & 1151.3 & 1140.0 & 1126.7 & 1114.7 & 1103.5 \\
60.00 & 1152.1 & 1140.8 & 1127.2 & 1115.6 & 1104.0 \\
80.00 & 1152.5 & 1141.4 & 1127.8 & 1116.6 & 1104.7 \\
100.00 & 1153.1 & 1142.0 & 1128.6 & 1117.3 & 1105.3 \\
150.00 & 1154.6 & 1143.5 & 1130.2 & 1118.9 & 1106.9 \\
200.00 & 1156.5 & 1145.0 & 1131.7 & 1120.5 & 1108.7 \\
250.00 & 1157.6 & 1146.6 & 1133.6 & 1122.0 & 1110.4 \\
300.00 & 1159.0 & 1148.1 & 1135.0 & 1123.6 & 1112.1 \\
350.00 & 1160.4 & 1149.6 & 1136.5 & 1125.2 & 1114.0 \\
\hline
\end{tabular}

Expanded uncertainty of the density $U(\rho)=1.5 \mathrm{~kg} \mathrm{~m}^{-3}$, expanded uncertainty of the temperature $U(T)=0.05 \mathrm{~K}$, expanded uncertainty of the pressure $U(P)=0.03$ bar, expanded uncertainty of the composition $U(x)=0.001$ with $k=2$.

Table 9: Densities of mixtures DMSO + AmimCl, $x_{\text {DMSO }}=0.098, x_{H 2 O}=0.016$.

Density / $\mathrm{kg} \mathrm{m}^{-3}$

\begin{tabular}{c|ccccc}
\hline \multirow{2}{*}{ Pressure / bar } & \multicolumn{5}{c}{ Temperature / K } \\
& 293.15 & 313.15 & 333.15 & 353.15 & 373.15 \\
\hline 1.00 & 1148.1 & 1136.2 & 1126.7 & 1114.8 & 1103.2 \\
5.00 & 1148.2 & 1136.3 & 1127.0 & 1115.2 & 1103.4 \\
10.00 & 1148.4 & 1136.7 & 1126.9 & 1115.0 & 1103.4 \\
20.00 & 1148.7 & 1136.9 & 1127.2 & 1115.2 & 1103.6 \\
30.00 & 1148.9 & 1137.1 & 1127.6 & 1115.6 & 1104.0 \\
40.00 & 1149.1 & 1137.4 & 1128.1 & 1115.9 & 1104.3 \\
60.00 & 1149.8 & 1138.1 & 1128.6 & 1116.5 & 1104.9 \\
80.00 & 1150.36 & 1138.6 & 1129.0 & 1117.3 & 1105.7 \\
100.00 & 1150.9 & 1139.3 & 1129.8 & 1117.9 & 1106.3 \\
150.00 & 1152.6 & 1140.8 & 1131.4 & 1119.9 & 1108.0 \\
\hline
\end{tabular}




\begin{tabular}{l|lllll}
\hline 200.00 & 1154.5 & 1142.4 & 1133.0 & 1121.4 & 1109.6 \\
250.00 & 1155.5 & 1143.9 & 1134.5 & 1122.8 & 1111.6 \\
300.00 & 1156.9 & 1145.4 & 1136.2 & 1124.5 & 1113.1 \\
350.00 & 1158.3 & 1146.6 & 1137.6 & 1126.0 & 1115.3 \\
\hline
\end{tabular}

Expanded uncertainty of the density $U(\rho)=1.5 \mathrm{~kg} \mathrm{~m}^{-3}$, expanded uncertainty of the temperature $U(T)=0.05 \mathrm{~K}$, expanded uncertainty of the pressure $U(P)=0.03$ bar, expanded uncertainty of the composition $U(x)=0.001$ with $k=2$.

Table 10: Densities of mixtures DMSO + AmimCl, $x_{D M S O}=0.048, x_{H 2 O}=0.015$.

Density / $\mathrm{kg} \mathrm{m}^{-3}$

\begin{tabular}{c|ccccc}
\hline \multirow{2}{*}{ Pressure / bar } & \multicolumn{5}{c}{ Temperature / K } \\
\hline & 293.15 & 313.15 & 333.15 & 353.15 & 373.15 \\
\hline 1.00 & 1149.3 & 1138.2 & 1128.2 & 1115.5 & 1104.2 \\
5.00 & 1149.8 & 1138.3 & 1128.3 & 1116.3 & 1104.7 \\
10.00 & 1149.9 & 1138.5 & 1128.6 & 1116.2 & 1104.8 \\
20.00 & 1150.0 & 1139.0 & 1128.5 & 1116.2 & 1104.8 \\
30.00 & 1150.2 & 1139.4 & 1128.9 & 1116.4 & 1105.5 \\
40.00 & 1150.5 & 1139.3 & 1129.2 & 1116.8 & 1105.8 \\
60.00 & 1151.1 & 1140.0 & 1129.5 & 1117.6 & 1106.0 \\
80.00 & 1151.7 & 1140.5 & 1129.9 & 1118.3 & 1106.9 \\
100.00 & 1152.3 & 1141.1 & 1130.6 & 1119.0 & 1107.4 \\
150.00 & 1153.7 & 1142.7 & 1132.1 & 1120.4 & 1109.3 \\
200.00 & 1155.6 & 1144.1 & 1133.7 & 1122.2 & 1110.2 \\
250.00 & 1156.6 & 1145.7 & 1135.4 & 1123.7 & 1112.6 \\
300.00 & 1158.1 & 1147.0 & 1136.7 & 1125.6 & 1114.4 \\
350.00 & 1159.3 & 1148.6 & 1138.2 & 1126.9 & 1116.1 \\
\hline
\end{tabular}

Expanded uncertainty of the density $U(\rho)=1.5 \mathrm{~kg} \mathrm{~m}^{-3}$, expanded uncertainty of the temperature $U(T)=0.05 \mathrm{~K}$, expanded uncertainty of the pressure $U(P)=0.03$ bar, expanded uncertainty of the composition $U(x)=0.001$ with $k=2$.

Table 11: Densities of pure AmimCl. $x_{H 2 O}=0.013$.

Density / $\mathrm{kg} \mathrm{m}^{-3}$

\begin{tabular}{c|ccccc}
\hline \multirow{2}{*}{ Pressure / bar } & \multicolumn{5}{c}{ Temperature / K } \\
& 293.15 & 313.15 & 333.15 & 353.15 & 373.15 \\
\hline 1.00 & 1149.9 & 1139.0 & 1129.4 & 1117.3 & 1106.0 \\
\hline
\end{tabular}




\begin{tabular}{l|lllll}
\hline 5.00 & 1150.0 & 1139.1 & 1129.4 & 1117.8 & 1106.4 \\
10.00 & 1150.2 & 1139.4 & 1129.5 & 1117.5 & 1106.5 \\
20.00 & 1150.5 & 1139.6 & 1129.8 & 1117.7 & 1106.7 \\
30.00 & 1150.7 & 1139.8 & 1130.0 & 1118.2 & 1107.3 \\
40.00 & 1151.0 & 1140.2 & 1130.4 & 1118.2 & 1107.4 \\
60.00 & 1151.6 & 1140.8 & 1131.1 & 1118.9 & 1107.9 \\
80.00 & 1152.2 & 1141.4 & 1131.5 & 1119.5 & 1108.6 \\
100.00 & 1152.8 & 1142.2 & 1132.1 & 1120.3 & 1109.4 \\
150.00 & 1154.1 & 1143.6 & 1133.7 & 1121.9 & 1110.8 \\
200.00 & 1155.9 & 1145.0 & 1135.1 & 1123.5 & 1112.6 \\
250.00 & 1157.0 & 1146.7 & 1136.7 & 1124.9 & 1114.2 \\
300.00 & 1158.3 & 1148.0 & 1138.2 & 1126.8 & 1116.1 \\
350.00 & 1159.7 & 1149.5 & 1139.7 & 1127.9 & 1117.7 \\
\hline
\end{tabular}

Expanded uncertainty of the density $U(\rho)=1.5 \mathrm{~kg} \mathrm{~m}^{-3}$, expanded uncertainty of the temperature $U(T)=0.05 \mathrm{~K}$, expanded uncertainty of the pressure $U(P)=0.03$ bar, expanded uncertainty of the composition $U(x)=0.001$ with $k=2$.

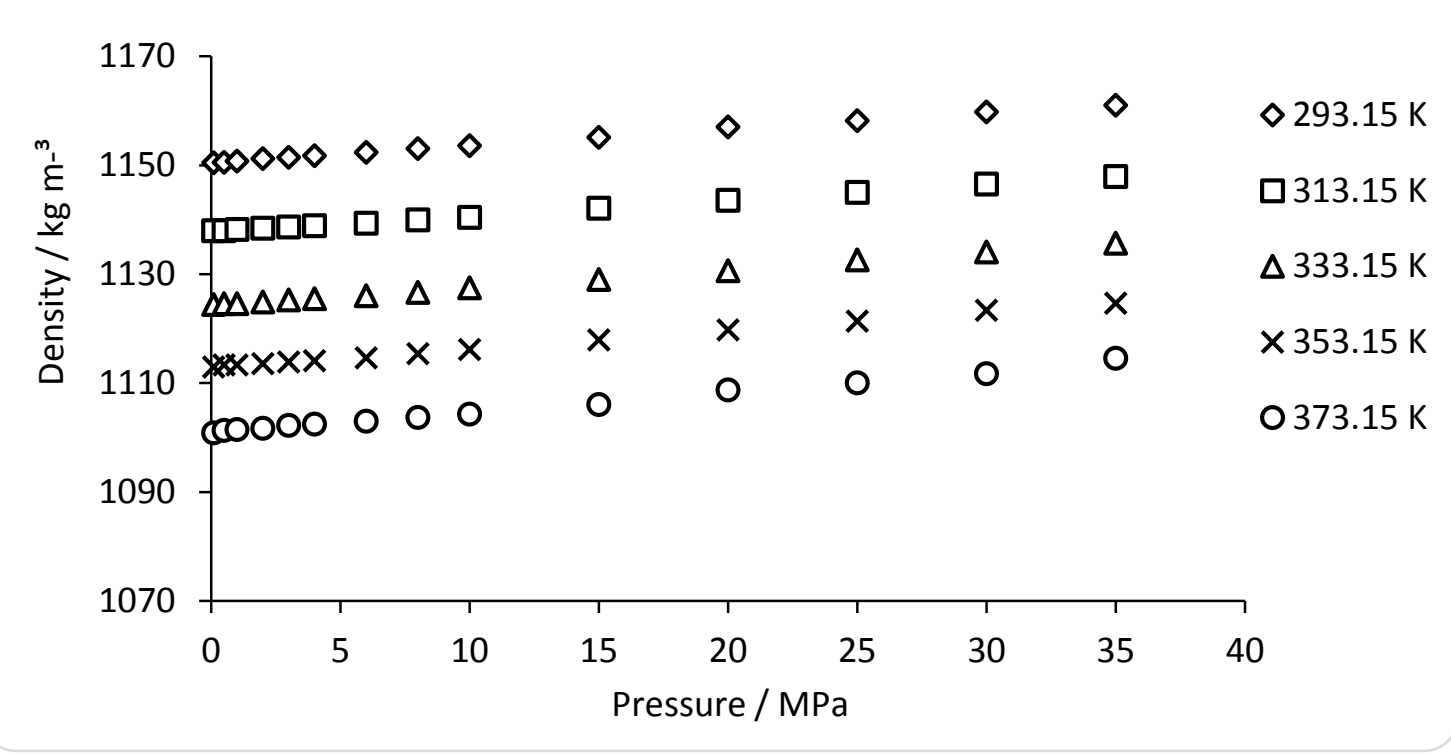

Figure 2: Densities of mixture 0.729 molar fraction of DMSO.

In Table 12 a comparison between the densities obtained in this work by the VTD and the data from Jiménez et al. [23] obtained using a Stabinger viscosimeter-densimeter at atmospheric pressure is presented. Both set of data are consistent.

Table 12: Comparison between densities measured in this work and from Jiménez et al.[23]. 


\begin{tabular}{ccc}
\hline Temp. & $\begin{array}{c}\text { Density, Jiménez et al [23] } \\
\text { Xwater }_{\text {w }}=0.045 . \\
\mathrm{g} \mathrm{cm}^{-3}\end{array}$ & $\begin{array}{c}\text { Density, this work } \\
\text { xwater }^{-}=0.013 \\
\mathrm{~g} \mathrm{~cm}^{-3}\end{array}$ \\
\hline 323.15 & 1.131 & \\
333.15 & 1.125 & 1.129 \\
343.15 & 1.119 & \\
353.15 & 1.114 & 1.117 \\
363.15 & 1.108 & \\
373.15 & 1.103 & 1.106 \\
\hline
\end{tabular}

In Figure 3, densities measured at $6 \mathrm{MPa}$ are plotted versus DMSO composition at various temperatures. It is observed that the density is decreasing with DMSO molar function. Small scattering in the data at concentrations between 0.05 and 0.25 are observed and were attributed to the different water content of the samples used.

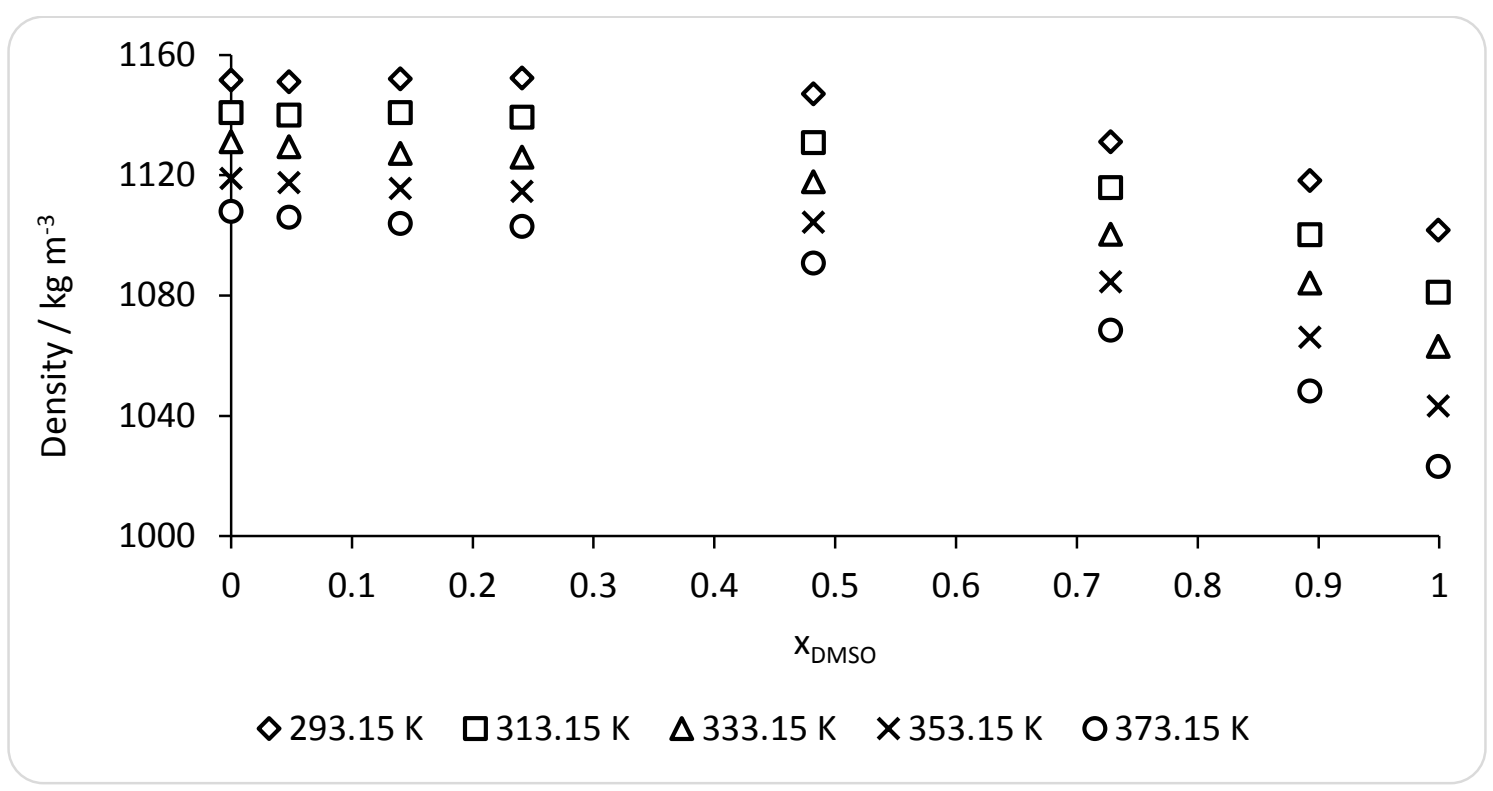

Figure 3: Density of mixtures at 6 MPa and various temperatures 
In Figure 4 it is represented the density of mixtures at $333.15 \mathrm{~K}$ as a function of DMSO composition at various pressures. The density also decreases with the molar fraction of DMSO and it increases with the pressure. This behavior is observed in all the temperatures.

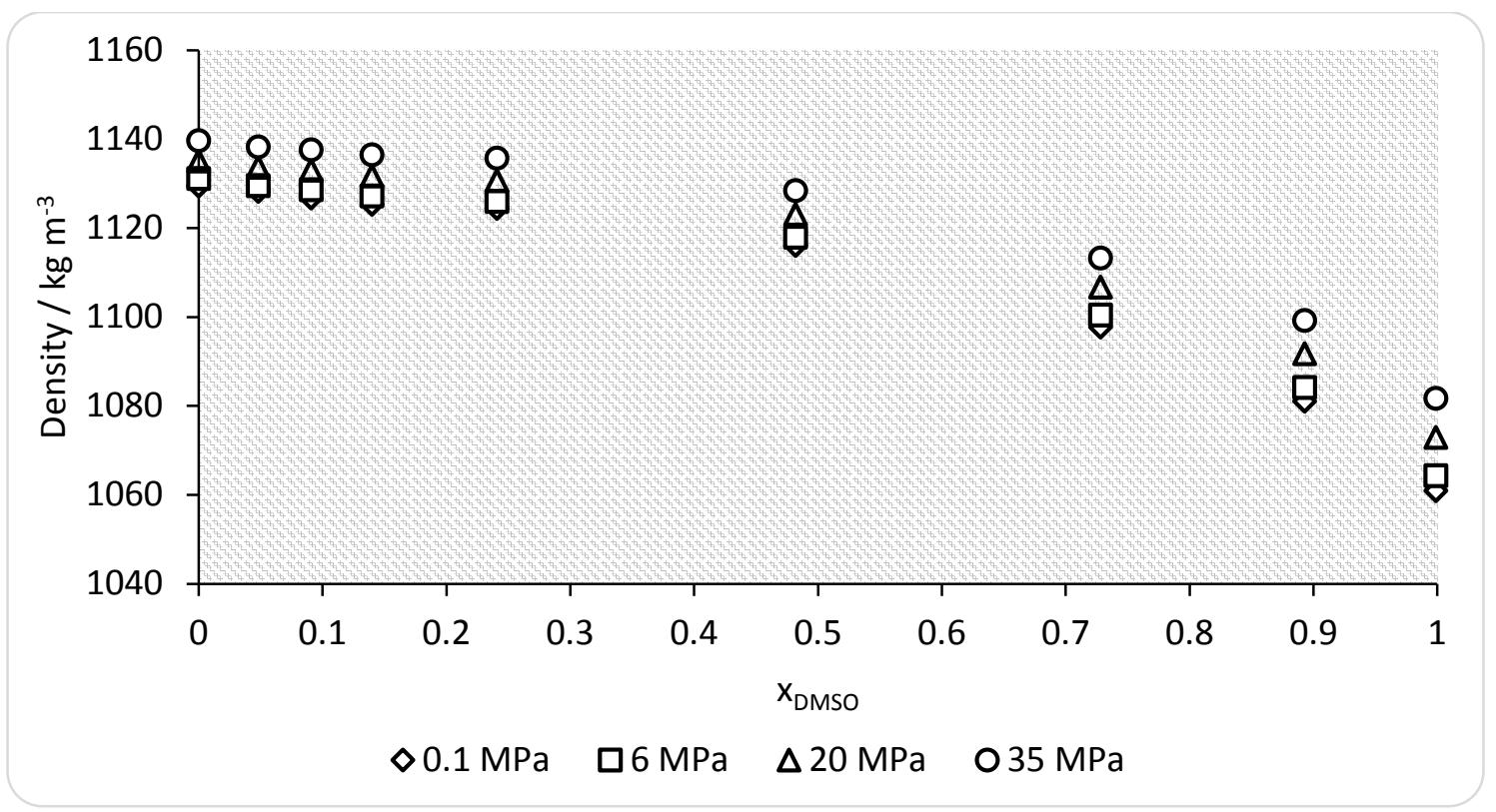

Figure 4: Density of mixtures at $333.15 \mathrm{~K}$ and various pressures. 


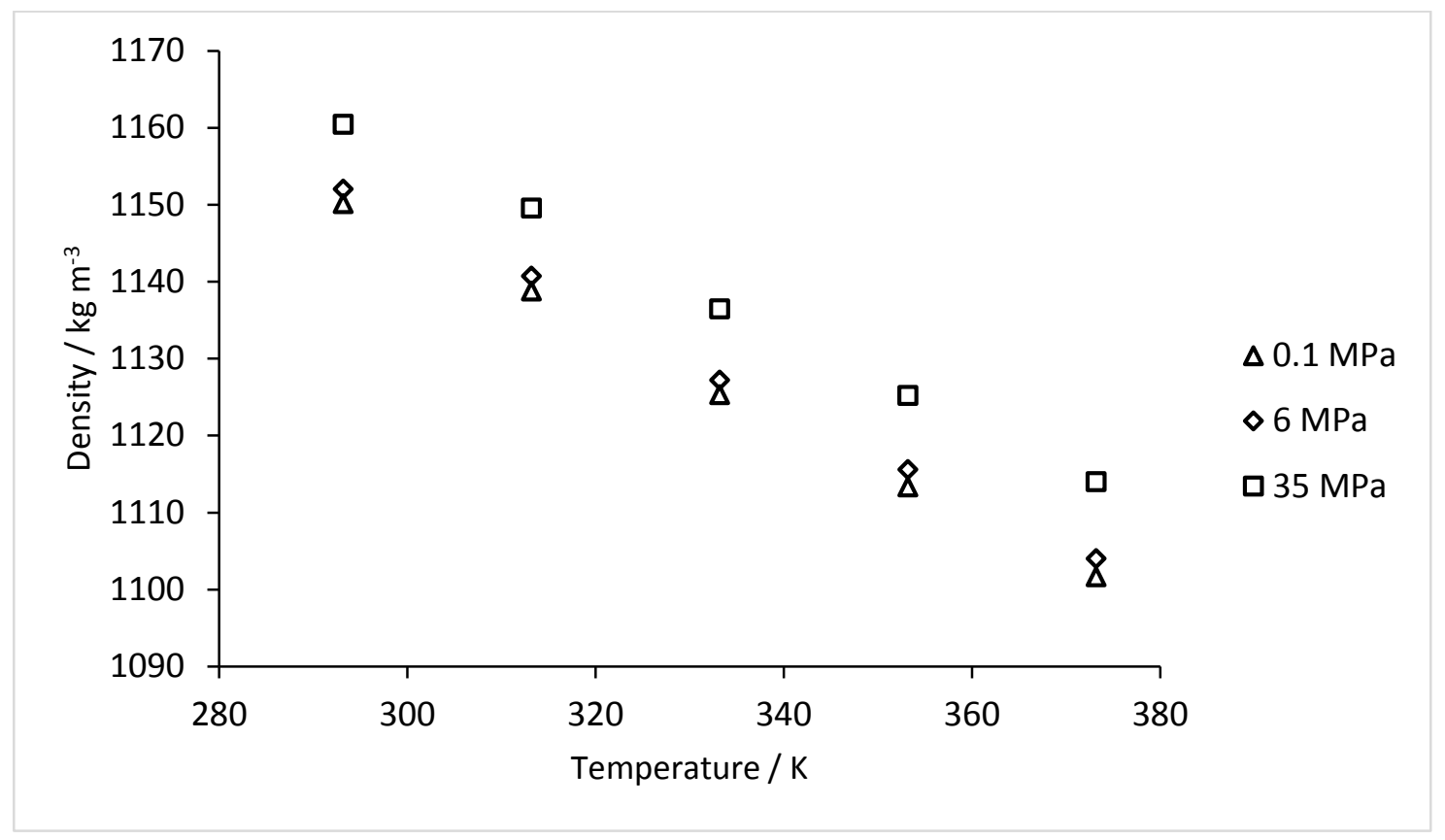

Figure 5: Density of mixture $x_{D M S O}=0.147$ at different pressures

The Figure 5 shows that the density also presents a linear tendency with the temperature.

\subsection{Excess molar volume}

Molar volumes were calculated considering the difference between the experimental and the theoretical value, using equation ( 2 ) the contribution of the water in the mixtures was taken into account.

$$
\begin{gathered}
V_{m}^{E}=V_{m}-V_{m}^{i d}=\frac{x_{I L} M_{I L}+x_{D M S O} M_{D M S O}+x_{H_{2} O} M_{H_{2} O}}{\rho^{\text {exp }}}-\left(x_{I L} \frac{M_{I L}}{\rho_{I L}^{\text {pure }}}+x_{D M S O} \frac{M_{D M S O}}{\rho_{D M S O}^{\text {pure }}}+\right. \\
\left.x_{\mathrm{H}_{2} \mathrm{O}} \frac{M_{\mathrm{H}_{2} \mathrm{O}}}{\rho_{\mathrm{H}_{2} \mathrm{O}}^{\text {pure }}}\right)
\end{gathered}
$$

Where $M_{I L}, M_{H 2 O}$ and $M_{D M S O}$ are the molar weights of the components, and $V_{m}$ is the experimental molar volume and $V_{m}^{\text {id }}$ is the ideal molar volume both in $\mathrm{cm}^{3} \mathrm{~mol}^{-1}$. Water density data were taken from Refprop [37]. Density of DMSO was measured in this work. In the case of the IL a linear tendency was assumed to obtain the density of the pure substance. 


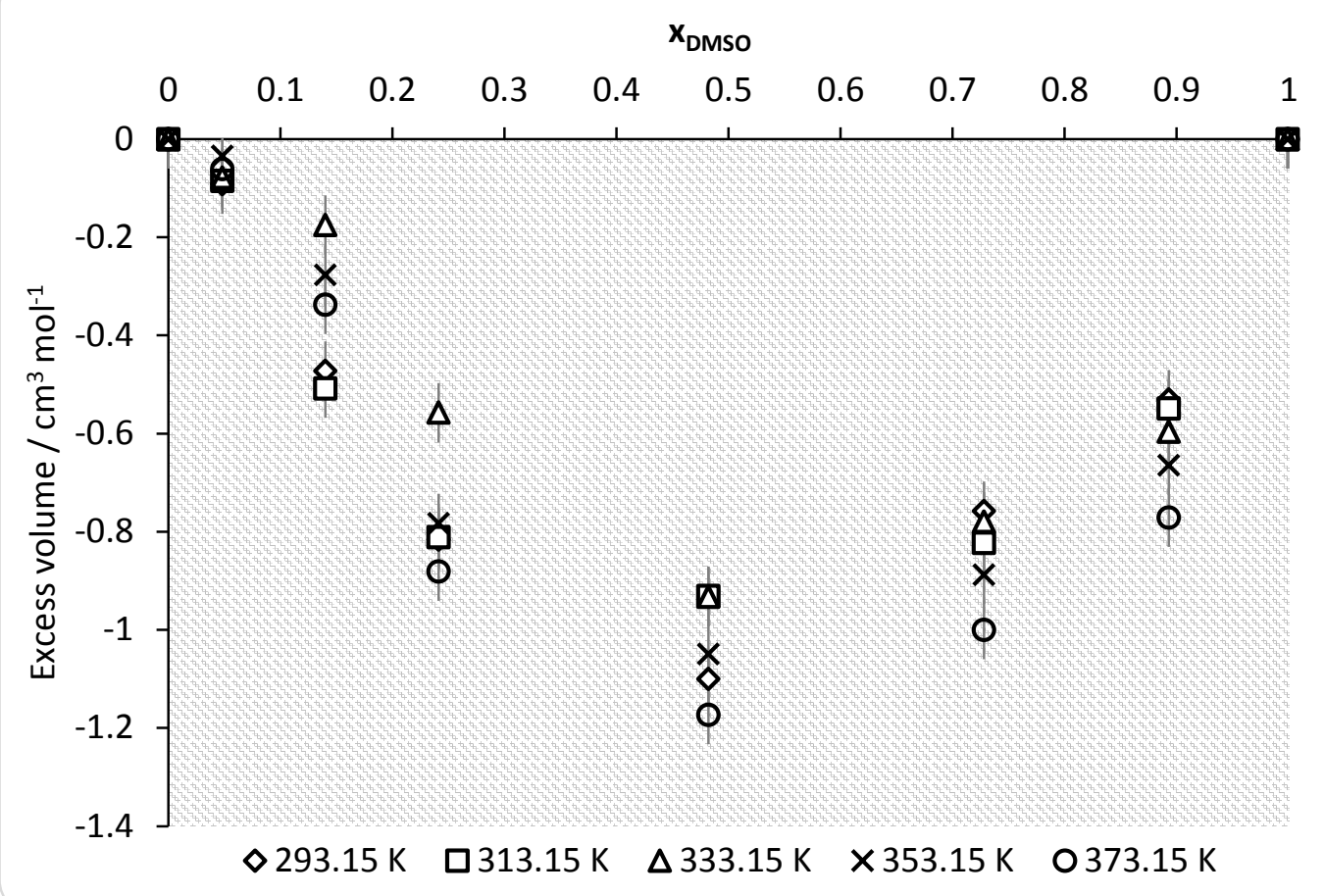

Figure 6: Excess molar volume in mixtures DMSO + AmimCl at 0.1MPa.

Excess molar volumes at atmospheric pressures are plotted versus DMSO concentrations at various molar fractions in Figure 7. It is observed that excess molar volume has a minimum around 0.5 molar fraction. It is well known that the mixtures of other molecular solvents with chloride based ILs such as water + Imidazolium chloride ILs have a significant negative excess molar volume and present a minimum around the concentration of $0.5-0.7$ molar fraction of water $[20,23,42,43]$.

In the case of DMSO + AmimCl this curve is more negative compared to the same ionic liquid mixed with water [23]. The negative excess molar volume is due to the effect of packaging between molecules of DMSO and ionic liquid. They increase the packing of the structure and as a consequence, the density of the real mixture is higher than the theoretical one [11]. Beyond the minimum an increase of the molar fraction of DMSO, the excess of the molar volume tends again 
to zero because the presence of the DMSO or liquid solvents causes the attraction forces between the IL ions reduce, producing a certain expansion of the fluids [34,44].

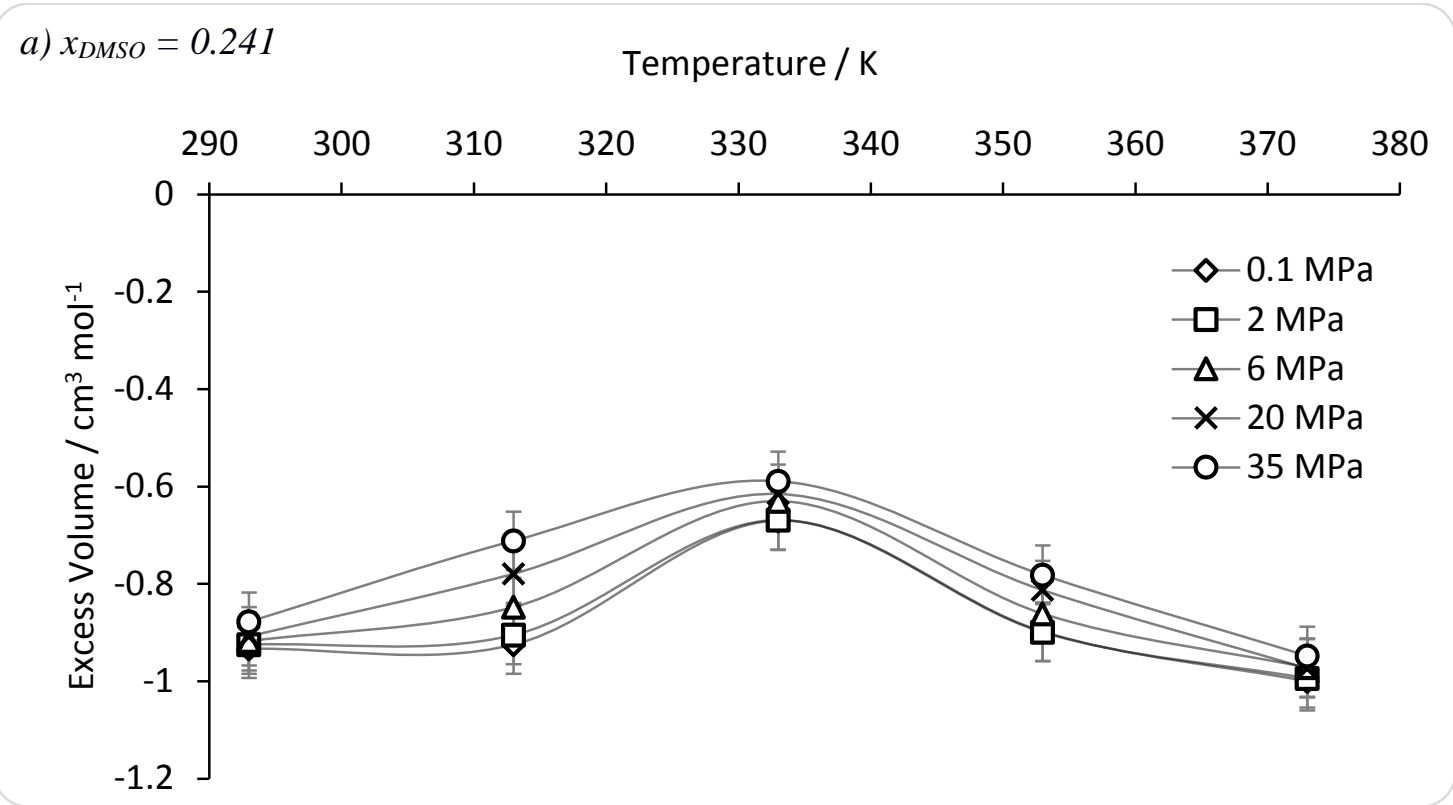


b) $x_{D M S O}=0.140$

Temperature / $\mathrm{K}$

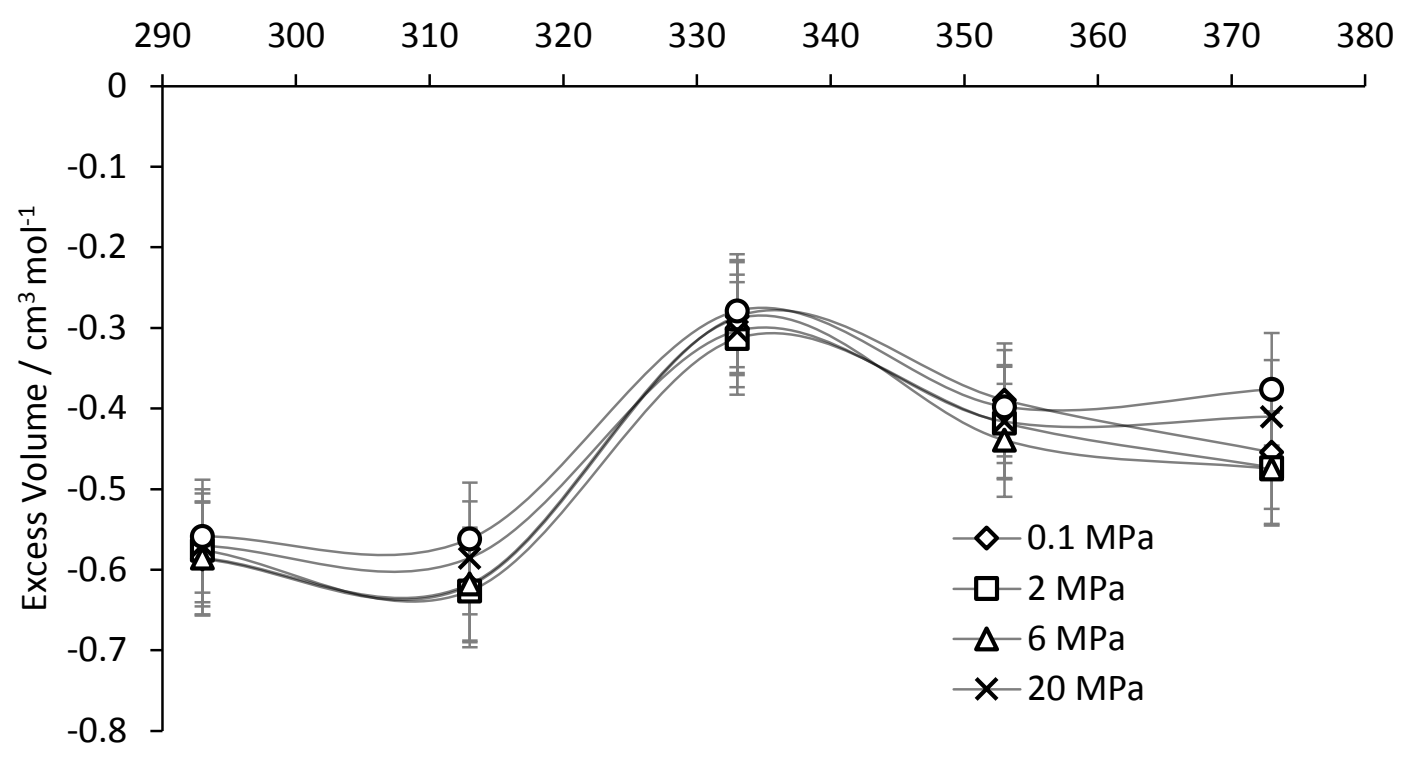

Figure 7: Influence of temperature in the excess molar volume in the mixture for a) $x_{D M S O}=$ 0.241 and $b$ ) $x_{D M S O}=0.14$. The lines are drawn as a guide to the data .

In Figure 7 the excess molar volumes of the mixtures with molar fractions of 0.241 and 0.140 of DMSO are represented as a function of temperature at various pressures. As it can be seen from Figure 7, the excess molar volume presents a maximum when it approximates to $333.15 \mathrm{~K}$, temperature near the melting point of the IL (324 K according to Lopes et al [45]). This behavior was found in more concentrations as is shown in Figure 8, being more pronounced at concentrations from 0.048 to 0.482 . To the best or our knowledge, this behavior has not been described by others authors before. 


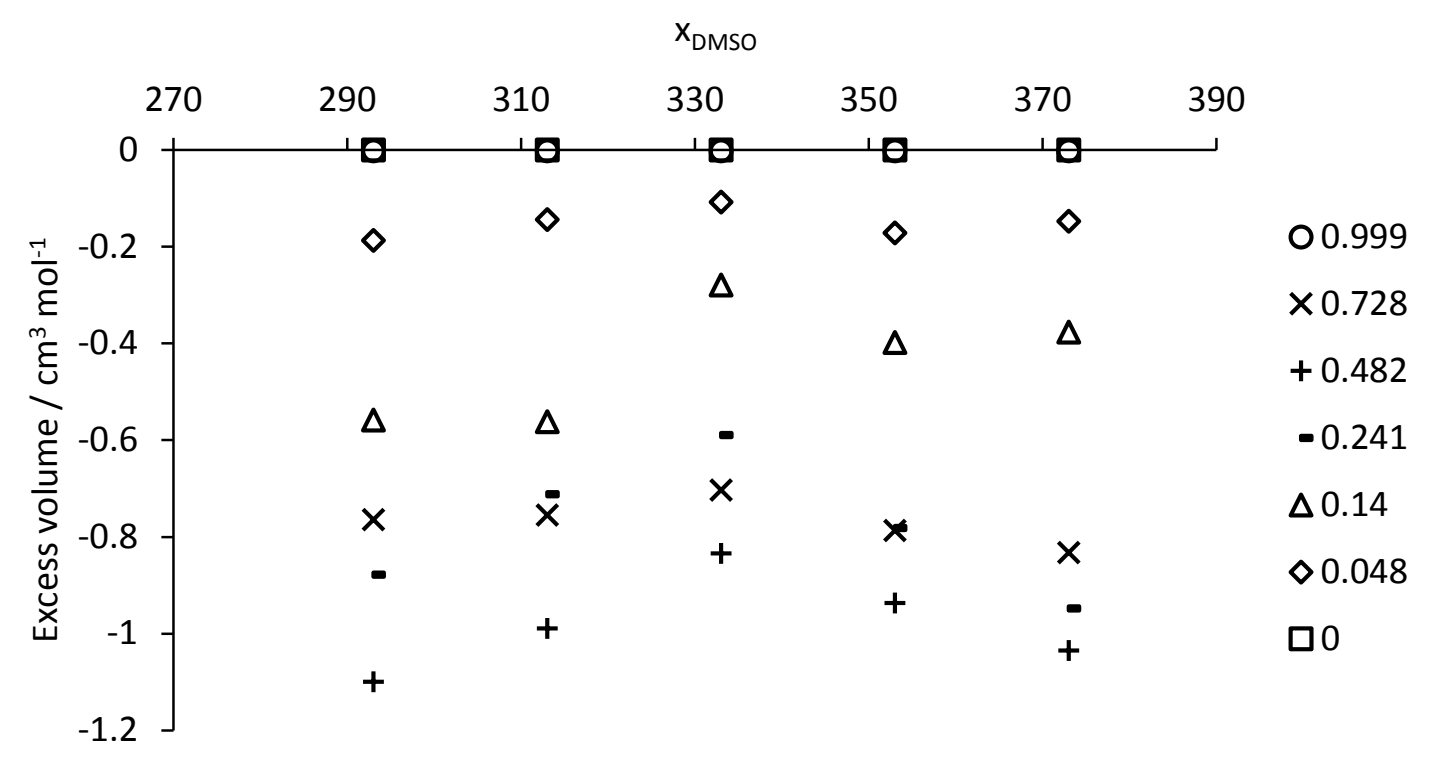

Figure 8: Excess molar volume at 35 MPa at different concentrations.

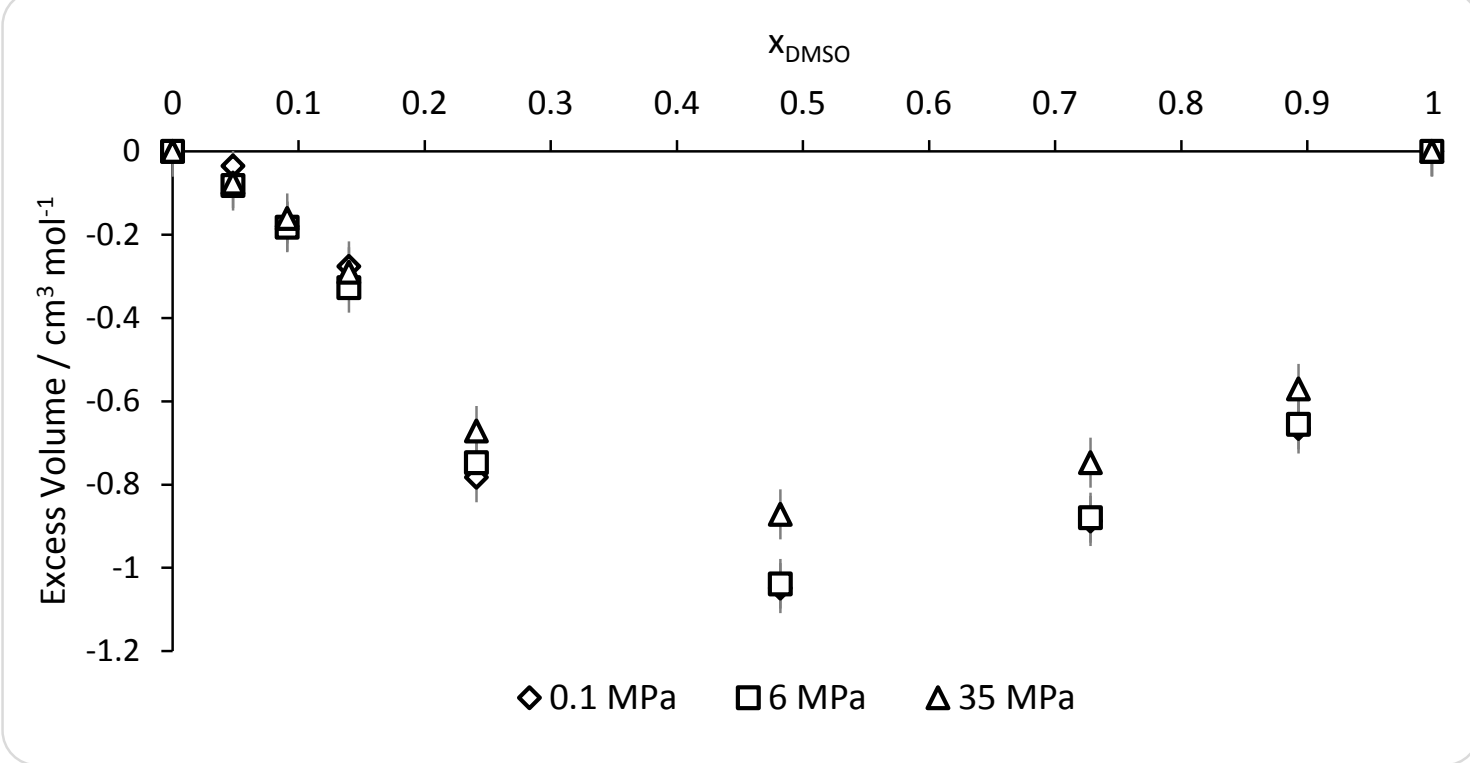

Figure 9: Excess molar volume in mixtures DMSO + AmimCl at $333.15 \mathrm{~K}$. 
In Figure 9 excess molar volume was plotted versus DMSO molar fraction. In general the pressure has a small influence in the excess volume, that decreases slightly with the pressure, being the slight molar volumes more negatives at lower pressures as observed in Figure 7 and Figure 9.

\subsection{Density correlation of mixtures DMSO + AmimCl}

The data were adjusted to an empirical correlation as a function of the temperature, the pressure and the composition.

Where:

$$
\begin{gathered}
\rho=A+B \cdot P+C \cdot T \\
A=A_{1} \cdot x_{D M S O}+A_{2} \\
B=B_{1} \cdot x_{D M S O}^{2}+B_{2} \cdot x_{D M S O}+B_{3} \\
C=C_{1} \cdot x_{D M S O}^{2}+C_{2} \cdot x_{D M S O}+C_{3} \\
A R D \%=\frac{\sum\left(\frac{\left|\rho_{\text {exp }}-\rho_{\text {calc }}\right|}{\rho_{\text {exp }}}\right)}{n} \cdot 100
\end{gathered}
$$

The correlated parameters are shown in Table 13.

Table 13: Correlated parameters of the equation ( 3 )

\begin{tabular}{|c|c|}
\hline $\mathrm{A}_{1}$ & 63.87 \\
\hline $\mathrm{A}_{2}$ & 1311.39 \\
\hline $\mathrm{B}_{1}$ & 0.302 \\
\hline $\mathrm{B}_{2}$ & -0.0128 \\
\hline $\mathrm{B}_{3}$ & 0.31 \\
\hline $\mathrm{C}_{1}$ & -0.2575 \\
\hline $\mathrm{C}_{2}$ & -0.1255 \\
\hline $\mathrm{C}_{3}$ & -0.5560 \\
\hline \%ARD & $0.12 \%$ \\
\hline \%MAX & $0.51 \%$ \\
\hline
\end{tabular}


The value of the \%ARD implies an excellent description of the studied system. The comparison between the experimental and the correlated are represented in Figure 10 and Figure 11.

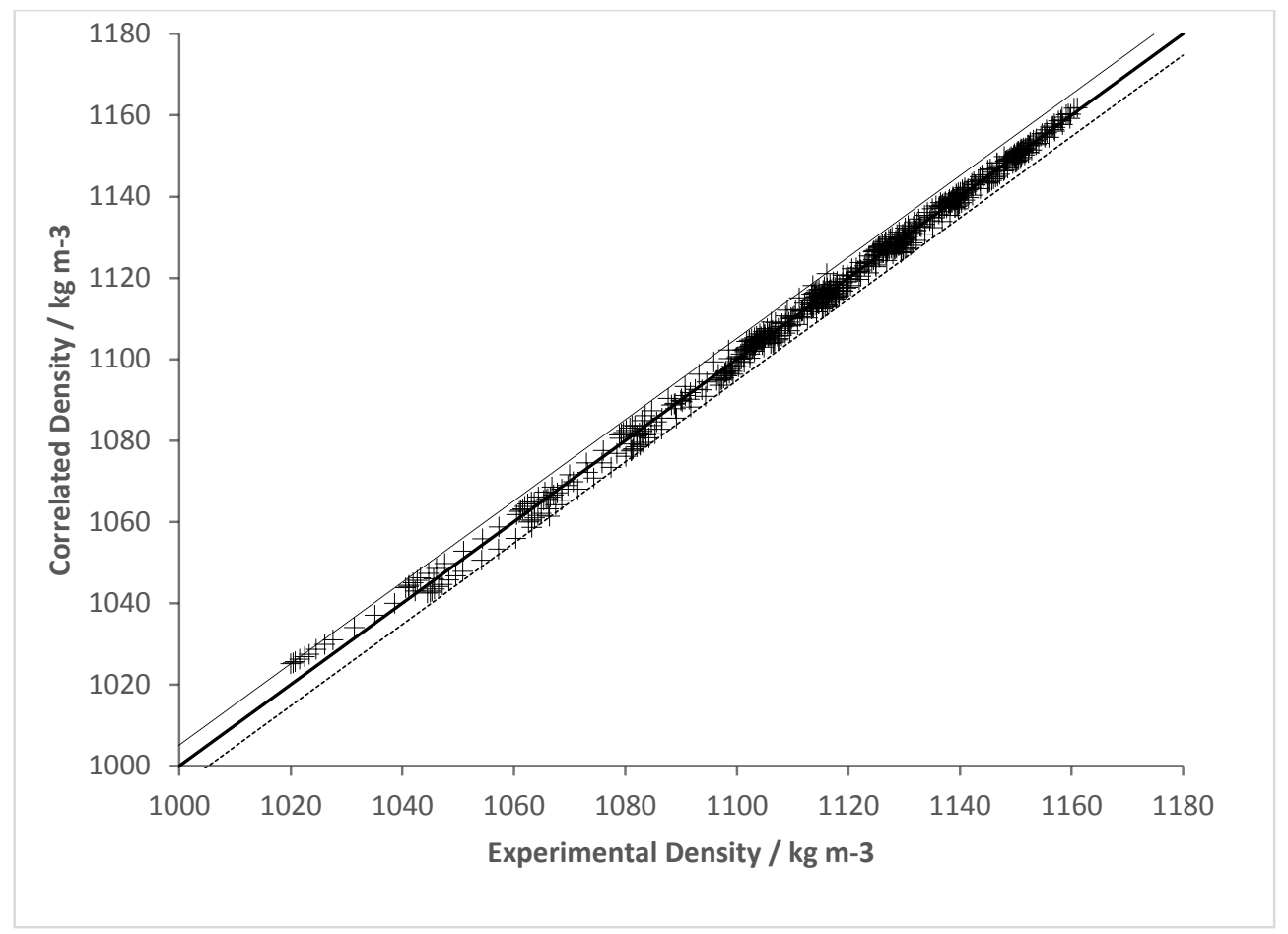

Figure 10: Comparison between the experimental data and the correlated with equation ( 3 ).Dotted lines represents $0.51 \%$ of maximum deviation. 


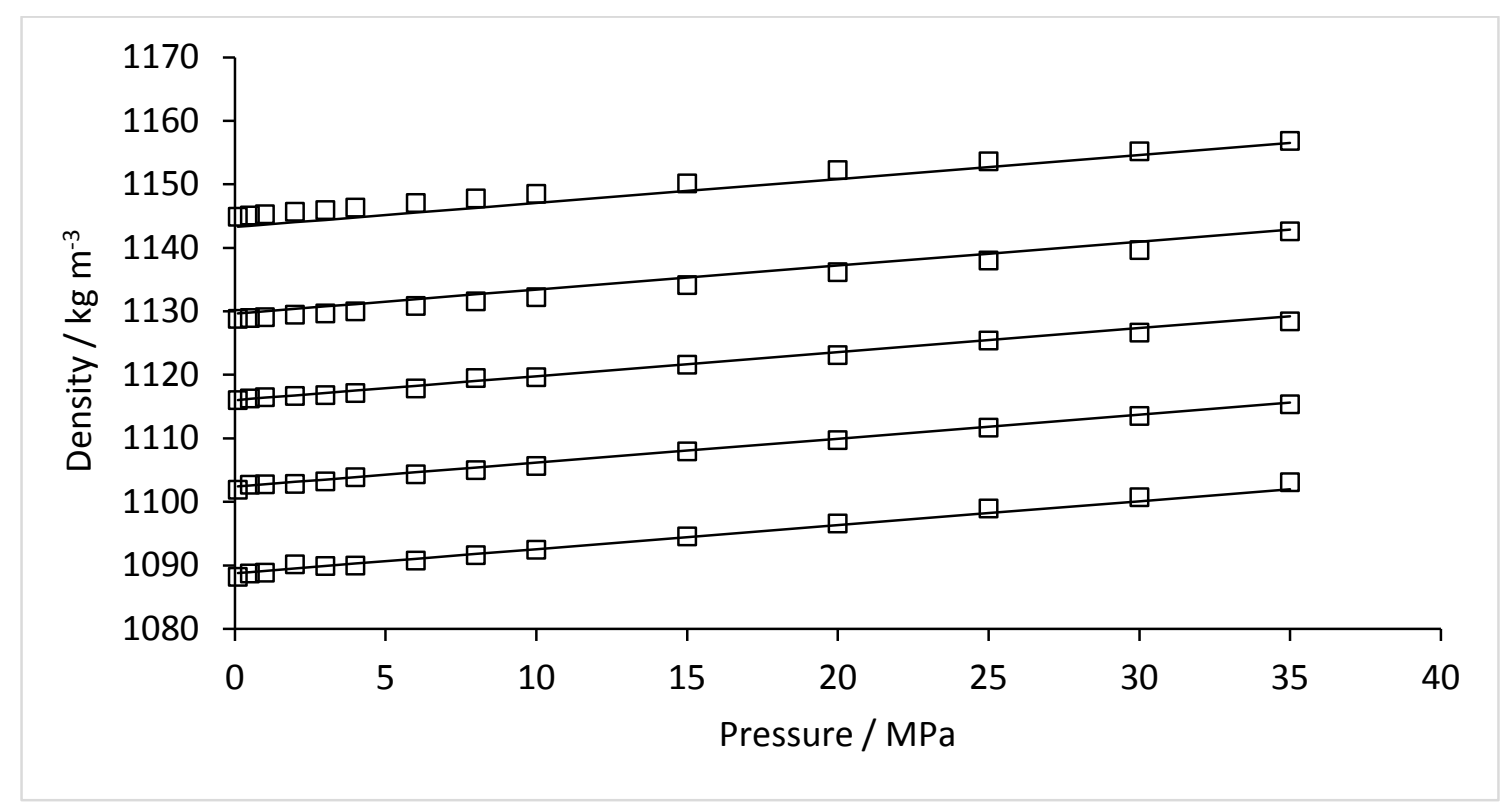

Figure 11: Comparison between the experimental and the correlated data at different temperatures; open squares, experimental data; lines, correlated data for the mixture $x_{D M S O}=0.496$.

\section{Conclusions}

In this work density and excess molar volume of mixtures of dimethyl sulfoxide (DMSO) with 1allyl-3-metkylimidazolium chloride (AmimCl) at a wide range of concentrations (molar fraction $\mathrm{x}_{\text {DMSO }}=0.0 .05$ 0.1. 0.15. 0.25. 0.5. 0.75. 0.9 and 1 ), temperatures (293.15 to 373.15) $\mathrm{K}$ and pressures (0.1 to $35 \mathrm{MPa}$ ) were determined. The density has a linear tendency with pressure and temperature, increasing with the ionic liquid concentration and with the pressure, and decreasing with the temperature.

Excess molar volumes of the mixtures were found to be negative with a minimum around $\mathrm{x}_{\mathrm{DMSO}}$ $=0.5$. This fact indicates that molecules of DMSO and AmimCl at this concentration have a better "packaging degree" between them. The Excess molar volume is slightly more negative at lower 
pressure. It was observed for first time that the excess molar volume has a maximum at 333.15 K for several DMSO concentrations.

Density was correlated as a function of the temperature, pressure and composition of the mixture. A good fitting has been achieved with an \%ARD $=0.12 \%$.

\section{Acknowledgements}

Authors thank the Junta de Castilla y León for funding through the project VA295U14. MDB thanks the Spanish Ministry of Economy and Competitiveness for the Ramón y Cajal research fellowship.

\section{References}

[1] J.D. Holbrey, K.R. Seddon, Ionic Liquids, Clean Technol. Environ. Policy. 1 (1999) 223236. doi:10.1007/s100980050036.

[2] K.N. Marsh, J.A. Boxall, R. Lichtenthaler, Room temperature ionic liquids and their mixtures - A review, Fluid Phase Equilib. 219 (2004) 93-98. doi:10.1016/j.fluid.2004.02.003.

[3] A. Pinkert, K.N. Marsh, S. Pang, M.P. Staiger, Ionic liquids and their interaction with cellulose, Chem. Rev. 109 (2009) 6712-6728. doi:10.1021/cr9001947.

[4] M. Parra Jimenez de la, Cristina; Navarrete, Alexander; Dolores Bermejo, M. Jose Cocero, Patents Review on Lignocellulosic Biomass Processing Using Ionic Liquids, Recent Pat. 
Eng. 6 (2012) 159-182. doi:10.2174/187221212804583231.

[5] J. Vitz, T. Erdmenger, C. Haensch, U.S. Schubert, Extended dissolution studies of cellulose in imidazolium based ionic liquids, Green Chem. 11 (2009) 417. doi:10.1039/b818061j.

[6] S. Zhu, Y. Wu, Q. Chen, Z. Yu, C. Wang, S. Jin, Y. Ding, G. Wu, Dissolution of cellulose with ionic liquids and its application: a mini-review, Green Chem. 8 (2006) 325. doi:10.1039/b601395c.

[7] Z. Meng, X. Zheng, K. Tang, J. Liu, S. Qin, Dissolution of natural polymers in ionic liquids: A review, E-Polymers. (2012) 1-29. doi:10.1515/epoly.2012.12.1.317.

[8] R. Sescousse, K.A. Le, M.E. Ries, T. Budtova, Viscosity of cellulose-imidazolium-based ionic liquid solutions, J. Phys. Chem. B. 114 (2010) 7222-7228. doi:10.1021/jp1024203.

[9] R. Jan, G.M. Rather, M.A. Bhat, Effect of cosolvent on bulk and interfacial characteristics of imidazolium based room temperature ionic liquids: Impact of cosolvent on physciochemical characteristics of ionic liquids, J. Solution Chem. 43 (2014) 685-695. doi:10.1007/s10953-014-0165-4.

[10] K.R. Seddon, A. Stark, M.-J.J.M.-J.M.-J.J.M.-J.M.-J.J. Torres, Influence of chloride, water, and organic solvents on the physical properties of ionic liquids, Pure Appl. Chem. 72 (2000) 2275-2287. doi:10.1351/pac200072122275.

[11] J. Wang, A. Zhu, Y. Zhao, K. Zhuo, Excess molar volumes and excess logarithm viscosities for binary mixtures of the ionic liquid 1-butyl-3-methylimidazolium hexaflurophosphate with some organic compounds, J. Solution Chem. 34 (2005) 585-596. doi:10.1007/s10953-005-5594-7.

[12] C. Cuissinat, P. Navard, T. Heinze, Swelling and dissolution of cellulose. Part IV: Free 
floating cotton and wood fibres in ionic liquids, Carbohydr. Polym. 72 (2008) 590-596. doi:10.1016/j.carbpol.2007.09.029.

[13] X. Wang, H. Li, Y. Cao, Q. Tang, Cellulose extraction from wood chip in an ionic liquid 1-allyl-3-methylimidazolium chloride (AmimCl), Bioresour. Technol. 102 (2011) 79597965. doi:10.1016/j.biortech.2011.05.064.

[14] D. a. Fort, R.C. Remsing, R.P. Swatloski, P. Moyna, G. Moyna, R.D. Rogers, Can ionic liquids dissolve wood? Processing and analysis of lignocellulosic materials with 1-nbutyl-3-methylimidazolium chloride, Green Chem. 9 (2007) 63. doi:10.1039/b607614a.

[15] Y. Lv, J. Wu, J.J. Zhang, Y. Niu, C.Y. Liu, J. He, J.J. Zhang, Rheological properties of cellulose/ionic liquid/dimethylsulfoxide (DMSO) solutions, Polymer (Guildf). 53 (2012) 2524-2531. doi:10.1016/j.polymer.2012.03.037.

[16] N. V. Sastry, N.M. Vaghela, P.M. Macwan, Densities, excess molar and partial molar volumes for water + 1-butyl- or, 1-hexyl- or, 1-octyl-3-methylimidazolium halide room temperature ionic liquids at $\mathrm{T}=(298.15$ and 308.15) K, J. Mol. Liq. 180 (2013) 12-18. doi:10.1016/j.molliq.2012.12.018.

[17] M. Tariq, F. Moscoso, F.J. Deive, A. Rodriguez, M.A. Sanromán, J.M.S.S. Esperança, J.N. Canongia Lopes, L.P.N. Rebelo, Probing the self-aggregation of ionic liquids in aqueous solutions using density and speed of sound data, J. Chem. Thermodyn. 59 (2013) 43-48. doi:10.1016/j.jct.2012.11.032.

[18] W. Liu, L. Cheng, Y. Zhang, H. Wang, M. Yu, The physical properties of aqueous solution of room-temperature ionic liquids based on imidazolium: Database and evaluation, J. Mol. Liq. 140 (2008) 68-72. doi:10.1016/j.molliq.2008.01.008.

[19] T. Singh, A. Kumar, Thermodynamics of dilute aqueous solutions of imidazolium based ionic liquids, J. Chem. Thermodyn. 43 (2011) 958-965. doi:10.1016/j.jct.2011.01.013. 
[20] E. Gómez, B. González, a Domínguez, E. Tojo, J. Tojo, Dynamic viscosities of a series of 1-alkylimidazolium chloride ionic liquids and their binary mixtures with water at several temperatures, J. Chem. Eng. Data. 51 (2006) 696-701.

[21] H. Xu, D. Zhao, P. Xu, F. Liu, G. Gao, Conductivity and viscosity of 1-Ally1-3-methylimidazolium Chloride + water and + ethanol from 293.15 K to 333.15 K, J. Chem. Eng. Data. 50 (2005) 133-135. doi:10.1021/je049787p.

[22] D. Wu, B. Wu, Y.M. Zhang, H.P. Wang, Density, Viscosity, Refractive Index and Conductivity of 1-Allyl-3-methylimidazolium Chloride + Water Mixture †, J. Chem. $\{\&\}$ Eng. Data. 55 (2010) 621-624. doi:10.1021/je900545v.

[23] C. Jiménez de la Parra, J.R. Zambrano, M.D. Bermejo, Á. Martín, J.J. Segovia, M.J. Cocero, Influence of water concentration in the viscosities and densities of cellulose dissolving ionic liquids. Correlation of viscosity data, J. Chem. Thermodyn. 91 (2015) 816. doi:10.1016/j.jct.2015.07.015.

[24] B. Kumar, T. Singh, K.S. Rao, A. Pal, A. Kumar, Thermodynamic and spectroscopic studies on binary mixtures ionic liquids in ethylene glycol, J. Chem. Thermodyn. 44 (2012) 121-127. doi:10.1016/j.jct.2011.08.008.

[25] J.M. Lopes, S. Kareth, M.D. Bermejo, Á. Martín, E. Weidner, M.J. Cocero, Experimental determination of viscosities and densities of mixtures carbon dioxide + 1-allyl-3methylimidazolium chloride. Viscosity correlation, J. Supercrit. Fluids. 111 (2016) 9196. doi:10.1016/j.supflu.2015.12.013.

[26] L.I.N. Tomé, R.L. Gardas, P.J. Carvalho, M.J. Pastoriza-Gallego, M.M. Piñeiro, J.A.P. Coutinho, Measurements and correlation of high-pressure densities of phosphonium based ionic liquids, J. Chem. Eng. Data. 56 (2011) 2205-2217. doi:10.1021/je101232g.

[27] H. Machida, R. Taguchi, Y. Sato, J.R.L. Smith, Measurement and Correlation of High 
Pressure Densities of Ionic Liquids, 1-Ethyl-3-methylimidazolium l-Lactate ([emim][Lactate]), 2-Hydroxyethyl-trimethylammonium $\quad$ l-Lactate ([(C2H4OH)(CH3)3N][Lactate]), and 1-Butyl-3-methylimidazolium Chloride ([bmim][Cl], J. Chem. Eng. Data. 56 (2010) 923-928. doi:10.1021/je1008747.

[28] J. Safarov, M. Geppert-Rybczyńska, I. Kul, E. Hassel, Thermophysical properties of 1butyl-3-methylimidazolium acetate over a wide range of temperatures and pressures, Fluid Phase Equilib. 383 (2014) 144-155. doi:10.1016/j.fluid.2014.10.015.

[29] R.L. Gardas, H.F. Costa, M.G. Freire, P.J. Carvalho, I.M. Marrucho, I.M.A. Fonseca, A.G.M. Ferreira, J.A.P. Coutinho, Densities and derived thermodynamic properties of imidazolium-, pyridinium-, pyrrolidinium-, and piperidinium-based ionic liquids, J. Chem. Eng. Data. 53 (2008) 805-811. doi:10.1021/je700670k.

[30] M.R. Currás, P. Husson, A.A.H. Pádua, M.F. Costa Gomes, J. García, High-pressure densities of 2,2,2-trifluoroethanol + ionic liquid mixtures useful for possible applications in absorption cycles, Ind. Eng. Chem. Res. 53 (2014) 10791-10802. doi:10.1021/ie5008568.

[31] I.M. Abdulagatov, A. Tekin, J. Safarov, A. Shahverdiyev, E. Hassel, High-pressure densities and derived volumetric properties (excess, apparent, and partial molar volumes) of binary mixtures of \{methanol (1) + [BMIM][BF4] (2)\}, J. Chem. Thermodyn. 40 (2008) 1386-1401. doi:10.1016/j.jct.2008.05.005.

[32] E. Widowati, M.J. Lee, PVT properties for binary ionic liquids of 1-methyl-1propylpiperidinium bis(trifluoromethylsulfonyl)imide with anisole or acetophenone at pressures up to $50 \mathrm{MPa}$, J. Chem. Thermodyn. 49 (2012) 54-61. doi:10.1016/j.jct.2012.01.008.

[33] Y. Qiao, F. Yan, S. Xia, S. Yin, P. Ma, Densities and Viscosities of [Bmim] [PF 6 ] and 
Binary Systems $\left[\mathrm{Bmim}_{[}\right]\left[\mathrm{PF}_{6}\right]+$ Ethanol, $[\mathrm{Bmim}]\left[\mathrm{PF}_{6}\right]+$ Benzene at Several Temperatures and Pressures: Determined by the Falling-Ball Method, J. Chem. Eng. Data. 56 (2011) 2379-2385. doi:10.1021/je1012444.

[34] I. Bahadur, T.M. Letcher, S. Singh, G.G. Redhi, P. Venkatesu, D. Ramjugernath, Excess molar volumes of binary mixtures (an ionic liquid+water): A review, J. Chem. Thermodyn. 82 (2015) 34-46. doi:10.1016/j.jct.2014.10.003.

[35] M.S. Sandhya, C.N. Rao, K. Sivakumar, P. Bhanuprakash, P. Venkateswarlu, Effect of temperature and alkyl chain length on molecular interactions in the binary mixtures of 1ethyl-3-methylimidazolium methylsulphate with 1-alkanols (C3-C6), J. Mol. Liq. 222 (2016) 981-987. doi:10.1016/j.molliq.2016.08.002.

[36] B. Mokhtarani, A. Sharifi, H.R. Mortaheb, M. Mirzaei, M. Mafi, F. Sadeghian, Density and viscosity of pyridinium-based ionic liquids and their binary mixtures with water at several temperatures, J. Chem. Thermodyn. 41 (2009) 323-329. doi:10.1016/j.jct.2008.09.001.

[37] E.W. Lemmon, R. Span, Short Fundamental Equations of State for 20 Industrial Fluids, J. Chem. Eng. Data. 51 (2006) 785-850.

[38] J.J. Segovia, O. Fandiño, E.R. López, L. Lugo, M. Carmen Martín, J. Fernández, Automated densimetric system: Measurements and uncertainties for compressed fluids, J. Chem. Thermodyn. 41 (2009) 632-638. doi:10.1016/j.jct.2008.12.020.

[39] M.J.P. Comuñas, J.P. Bazile, A. Baylaucq, C. Boned, Density of Diethyl Adipate using a New Vibrating Tube Densimeter from (293.15 to 403.15) K and up to $140 \mathrm{MPa}$. Calibration and Measurements, J. Chem. Eng. Data. 53 (2008) 986-994.

[40] B. Lagourette, C. Boned, H. Saint-Guirons, P. Xans, H. Zhou, Densimeter calibration method versus temperature and pressure, Meas. Sci. Technol. 3 (1992) 699-703. 
[41] Joint Committee for Guides in Metrology, Evaluation of measurement data: Guide to the expression of uncertainty in measurement, Int. Organ. Stand. (2008). doi:10.1373/clinchem.2003.030528.

[42] X.-H. Fan, Y.-P. Chen, C.-S. Su, Densities and viscosities of binary liquid mixtures of 1ethyl-3-methylimidazolium tetrafluoroborate with acetone, methyl ethyl ketone, and Nmethyl-2-pyrrolidone, J. Taiwan Inst. Chem. Eng. 61 (2016) 117-123. doi:10.1016/j.jtice.2016.01.004.

[43] N. Zec, M. Bešter-Rogač, M. Vraneš, S. Gadžurić, Volumetric and viscosimetric properties of [bmim][DCA]+ $\gamma$-butyrolactone binary mixtures, J. Chem. Thermodyn. 97 (2016) 307-314. doi:10.1016/j.jct.2016.02.014.

[44] L. Chen, J. Chen, Z. Song, G. Cui, Y. Xu, X. Wang, J. Liu, Densities, viscosities, and excess properties of binary mixtures of two imidazolide anion functionalized ionic liquids with water at $\mathrm{T}=$ (293.15 to 313.15) K, J. Chem. Thermodyn. 91 (2015) 292-300. doi:10.1016/j.jct.2015.08.010.

[45] J.M. Lopes, F.A. Sánchez, S.B.R. Reartes, M.D. Bermejo, Á. Martín, M.J. Cocero, Melting point depression effect with CO2 in high melting temperature cellulose dissolving ionic liquids. Modeling with group contribution equation of state, J. Supercrit. Fluids. 107 (2016) 590-604. doi:10.1016/j.supflu.2015.07.021. 